\title{
Chapter 7 \\ The Teaching of Multidigit Multiplication in the Japanese Approach
}

\author{
Masami Isoda, Raimundo Olfos, and Takeshi Noine
}

This chapter illustrates the process of the teaching multi-digit multiplication in relation to Chap. 1, Fig. 1.1 as follows. Firstly, the diversity of multiplication in vertical form is explained in relation to the multiplier and multiplicand, and the Japanese approach in comparison with other countries such as Chile and the Netherlands is clearly illustrated. Secondly, how a Japanese teacher enables students to develop multiplication in vertical form beyond repeated addition is explained with an exemplar of lesson study. Thirdly, the exemplar illustrates a full-speck lesson plan under school-based lesson study which demonstrates how Japanese teachers try to develop students who learn mathematics by and for themselves including learning how to learn (see Chap. 1). Fourthly, it explains the process to extend multiplication in vertical form to multidigit numbers by referring to Gakko Tosho textbooks.

\footnotetext{
M. Isoda $(\square)$

CRICED, University of Tsukuba, Tsukuba, Ibaraki, Japan

e-mail: isoda@criced.tsukuba.ac.jp

R. Olfos

Mathematics Institute, Pontifical Catholic University of Valparaíso Science Faculty,

Valparaíso, V - Valparaiso, Chile

e-mail: raimundo.olfos@pucv.cl
}

T. Noine

University of Tsukuba, Tsukuba, Japan 


\subsection{Diversity of Column, Algorithm, and Vertical Form Methods for Multiplication}

There is a diversity of column multiplication in vertical form around the world; the terminology itself differs, such as "column methods" in UK English and "algorithm" or "long multiplication" in US English. As part of algebra, the expression $a \times b$ is standardized around the world even though some countries, such as Chile, prefer to write " $3 \bullet 4$ " for $3 \times 4$. On the other hand, there is no universal standardized form for multiplication in vertical form, as well as other operations in vertical form. For example, in Chile, Japan, and the Netherlands, $23 \times 7$ is written as shown in Fig. 7.1.

In Fig. 7.1, all approaches use row 7 of the multiplication table. Japan and the Netherlands do multiplication from the lower to the upper columns. The Chilean method is consistent with algebraic expressions. It is not exactly vertical, and it looks like a kind of memo if we compare it with others. The Chilean method calculates the ones first. The Japanese method asks students to devise various methods by themselves at the beginning and then later reduces the adding (intermediate) part in the process of extension to 2-digit multiplication. In the Japanese curriculum standards, thinking about how to calculate the operation is one of objective as well as understanding the meanings and getting proficiency. At the last moment, they compare and discuss about easiness or fastness. Students communicate and explain that, 14 means 140 because of place value; It is not read as "one hundred forty" but as "fourteen" as an adaptation of the multiplication table. If it just means $7 \times 2=14$ instead of $70 \times 2=140$, the way of calculation can be seen as an algorithm using the multiplication table on the place value. This is the reason why the column method is called as an algorithm. To get the answer, it is necessary to use the multiplication table but not repeated addition (see Meaning of B, Fig. 1.1 in Chap. 1). Both the Japanese and the Netherlands forms calculate from the lower digit to the upper digit. However, in the Netherlands, $7 \times 23$ means to apply the multiplication table and calculate from tens, which is also the way to avoid a contradiction in Indo-European languages (See Chap. 3). In the case of Japan, there are some students who calculate from the largest place value in vertical form even though it is a way for mental estimation which follows the east culture cultivated by their abacus. Students prefer to calculate from the ones as well as the case of addition and subtraction in vertical form ${ }^{1}$.

Here, these methods of multiplication are called column multiplication, an algorithm, or vertical form. For understanding of all kinds of column multiplication with such huge diversity, we provide a historical perspective and set conditions for what vertical form in multiplication is.

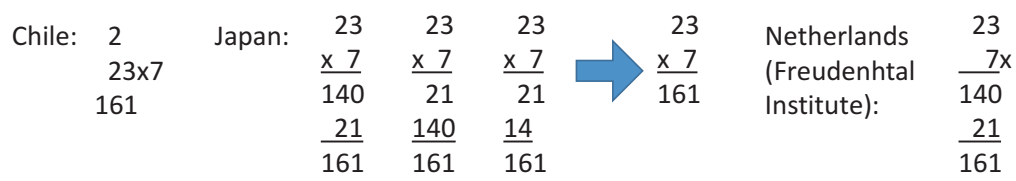

Fig. 7.1 Various vertical forms for multiplication

\footnotetext{
${ }^{1}$ Hulbert, E. T. et al (2017) also illustrated how progress students' mathematical writing of multiplication algorism under CCSSM in USA.
} 
Fig. 7.2 Arcavi and Isoda (2007) from Eric Peet

Hieroglyphs (1923)

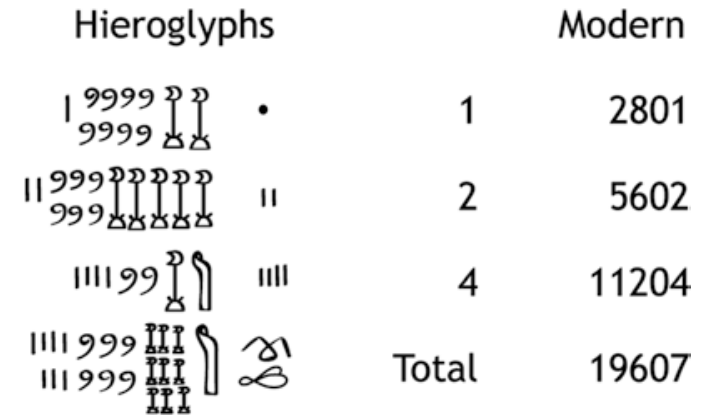

Modern

2801

5602

11204

19607

\subsubsection{Historical Illustration of Diversity}

The roots of vertical forms in calculation can be found in ancient civilizations. Historically, various vertical forms appeared before the unified algebraic notation for arithmetic operations.

For example, ancient Egyptians wrote numbers in vertical form with the idea of doubling (2 times). However, it is not our meaning of multiplication because it was not necessary for them to memorize the whole multiplication table for doubles (see Fig. 7.2 for revision of Problem 79 from the Rhind Papyrus, 1650 BCE).

From the modern perspective, the idea of proportional reasoning can be found between the lines of this Egyptian writing. However, the Egyptians used doubles.

In Euclid's Elements, there was a theory of proportion with measurement and multiples for proportional reasoning, in general. However, there was no current meaning of multiplication even though some English translations of Euclid's Elements have used that term. Current historians explain it by the term "multiple/multiplicity" (see Chap. 3). For example, we can find the same figure as Descartes's definition of multiplication (see Chap. 3 and Elements Chap. 6, Proposition 11). It was not the same as the current meaning of multiplication, which allows multiplication of different quantities, but a way of measurement such as to find a segment of a geometric mean.

Fibonacci's Liber Abaci (1202) in English edition (Sigler, 2002) is known as a book that influenced calculations in vertical form from East Asia and India through Arabia with Arabic numerals during that era. It is done by the base ten place value notation system using Arabic numerals. We should note that most people used counting boards before Liber Abaci because they provide the answer by manipulative counting. Arabic numerals were introduced in that era and the book of Fibonacci is known as a book that influenced innovative movements on arithmetic in Europe with the base ten place value notation system and column methods. Algebraic expression and the multiplication symbol " $x$ " were invented after the Renaissance, especially the symbol " $\times$ " was introduced by William Oughtred (1631; see Cajori, 1928). From that era, column calculation and the multiplication table gradually spread in Europe (Fig. 7.3). 
Fig. 7.3 Gregorio Reisch (1504), Margarita Philosophica. Argentineñ: Opera Joannis Schotti. Arabic column methods versus a counting board. (Chapter title page for arithmetic; no page numbers in this book)

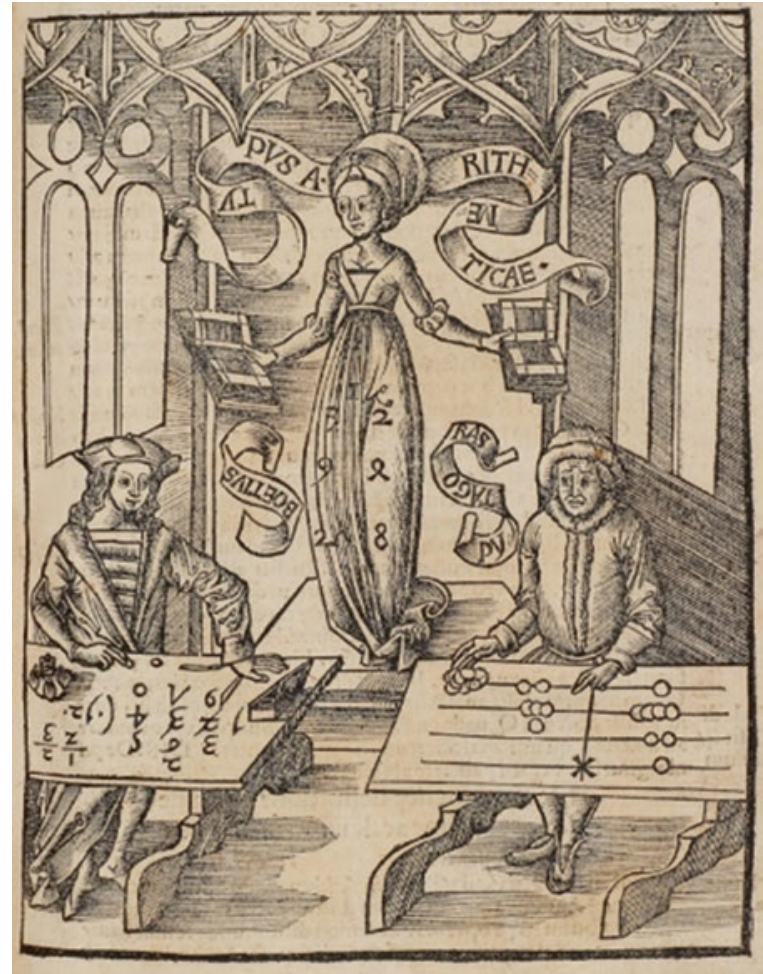

\begin{tabular}{|l|l|l|l|l|}
\hline First 4 & & $\begin{array}{l}\text { Second } 44 \\
12\end{array}$ & & $\begin{array}{l}\text { Third } 144 \\
12 \\
12\end{array}$ \\
\hline $\begin{array}{l}\text { (Explanation: } \\
2 \times 2 \text { on ones, } \\
\text { which corresponds } \\
\text { to the product of } \\
\text { ones) }\end{array}$ & & $\begin{array}{l}\text { (Explanation: } \\
1 \times 2+2 \times 1 \text { between } \\
\text { ones and tens, which } \\
\text { corresponds to the } \\
\text { product of tens) }\end{array}$ & & $\begin{array}{l}\text { (Explanation: } \\
1 \times 1 \text { on tens, } \\
\text { which corresponds } \\
\text { to the product of } \\
\text { hundreds) }\end{array}$ \\
\hline
\end{tabular}

Fig. 7.4 Fibonacci's Liber Abaci (Sigler, 2002, p. 24)

The first chapter of Liber Abaci explained addition and multiplication tables as well as the base ten place value notation system with Arabic numerals in comparison with Roman numerals. The multiplication table begins from row 2: 2 times 2 make 4, 236 (as 2 times 3 make 6), 24 8, up to 10 times 10 make 100 (no symbol between numbers). The second chapter is about multidigit multiplication in vertical form. The first example used to introduce multidigit multiplication was $12 \times 12$, the same 2-digit multiplication, which was explained by the process shown in Fig. 7.4. 
Fig. 7.5 Fibonacci's manner of one digit number multiplied by two digits number

$\begin{array}{rl}392 & \text { (Explanation: } \\ 8 & 8 \times 9=72,7 \text { in mind. } \\ 49 & 8 \times 4=32, \text { add } 7 \text { in mind) }\end{array}$

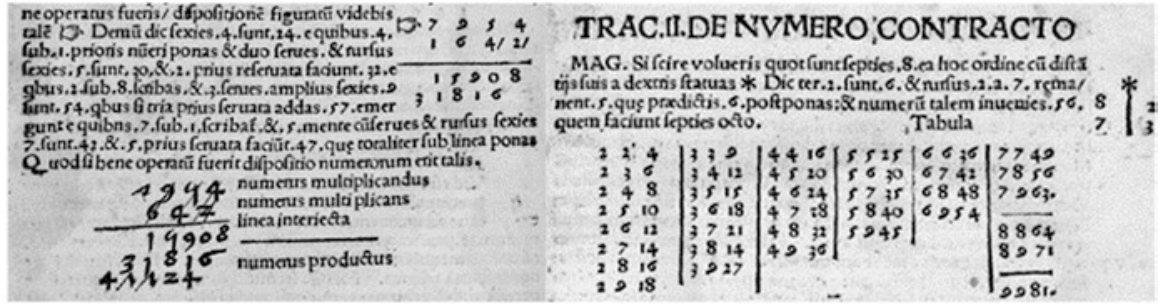

Fig. 7.6 Gregorio Reisch (1504), Margarita Philosophica. Argentineñ: Opera Joannis Schotti. (No page numbers in this book), The multiplication table, left of the figure, is not the whole table but a half and no row of 1

These steps show why it begins with multiplication of the same 2-digit numbers. It is for explaining how to set the place value for the product with the algorithm using the multiplication table. Thus, base ten place value system is the bases for vertical form. After such an example of the same 2-digit numbers, in the next section, multiplication of a 1-digit number by a 2-digit number is explained with $8 \times 49$ as an example (Fig. 7.5). In vertical form, 8 was written at first, then 49 was written below 8 , under the row (line) of 49 , and the answer (product) was written at the top. If we write the product in the bottom row (line) instead of in the top row (line), the format becomes the same as that of the Japanese (Fig. 7.1). On the other hand, if we read it from the bottom row to the top row, it looks like the reverse of the Netherlands method.

In Margarita Philosophica by Gregorio Reisch (1504), which was known as an essential textbook for liberal arts in the sixteenth century, the explanation of vertical form and the multiplication table shown in Fig. 7.6 can be seen. Before multiplication, it explains addition and subtraction of column methods. On addition in vertical form, it states, "augend upper line plus addend lower line.” In the same manner, in Fig. 7.6, the multiplicand is in the upper line and the multiple is in the lower line.

Before the Fig. 7.9, the multiplication section in Margarita Philosophica began as follows:

\footnotetext{
What is multiplication? Magnificent! It is to produce the proportional number correspond to multiplicand. It is multiple of unit. For example, a 3 by (per) 4, multiplier make number 12. It is the same proportion (ratio) 12 to 4 as 3 to unit. Because the ratio (proportion) of both, triple (thrice). ${ }^{2}$
}

\footnotetext{
${ }^{2}$ Verbi gratia 3 per 4 multiplicare est numerum 12 pro creare. Qui se in eadem proportione ad 4 habet sicut 3 ad unitatem. Quia utro bigs est proportio tripla. (No page numbers in this book).
} 
This definition of multiplication based on proportionality, as is Descartes's, which is the definition of multiplication by measurement (see the discussion in Chap. 3). In this book, multiplication was explained for people who already knew about ratios and proportions because there is a chapter of Geometry before this chapter for Arithmetic. Thus, their usage of terminology is not the same as today's. There was no algebraic expression but only vertical form with the base ten place value system and a multiplication table without algebraic symbols. The vertical form and table were the form for expressions. In this book, multiples ${ }^{3}$ and (set/cardinal) numbers are distinguished in the explanation. A number is represented by Arabic numerals and a multiple is represented by spelling out, such as "twice" (double), not represented as "2 times" by using Arabic numerals. The text sentences use a multiple such as "triple" which means 3 times. In a multiplication table such as "2 4 8" (see Fig. 7.6), it is read bis 4 sunt 8 ("twice 4 is 8 ") which means the multiplier functions as "number of times." At the rows on Fig. 7.6, right, the first number was used to be read as multiplicative numeral such as bis (twice). If multiplication is to produce the proportional number corresponding to the multiplicand, a further interpretation of the multiplication table on the right side of Fig. 7.6 could be to understand it as "3 412 " corresponding to " 1 to 3 is 4 to 12 "; for example, in the table, " 224 " implies " $1: 2=$ $2: 4$ " and "2 36 " implies " $1: 2=3: 6$ " (the algebraic expression did not exist in the text). ${ }^{4}$ On this notation, if first numbers on the table were read as multiplicative numeral, they may not feel necessary to use the symbol " $x$ " because the number of times such as "two times" is represented by multiplicative numeral "twice".

On the basis of this understanding, we would like to return to the problem of the multiplier and multiplicand which has been discussed since Chap. 2. If we compare the left and right sides of Fig. 7.6 and consider the correspondence, we find that the multiplication on the left corresponds to (multiplier) [space $(\times)$ ] (multiplicand) [space] (product) in the horizontal table on the right. In the table, the multiplier (numeral) is read as a multiple and the multiplicand is read as a number. It is a calculation in vertical form as (lower line: multiplier) $\times$ (upper line: multiplicand), which means it calculates from the lower row to the upper row in vertical form and the product is written under the lower row. The vertical form as a column method and the horizontal multiplication table function as mathematical forms instead of an algebraic expression at this era.

\footnotetext{
${ }^{3}$ In English, the difference between multiplier (single, double, and triple: adjectives) and multiplicative numbers (adverbs: once, twice, and thrice) are existed. Japanese does not these numerals (Ramsey, 1892, p339). In English, the multiple (number of times) is based on the natural number. In Japanese, multiplicative numeral is represented by times (bai) and bai is not limited to use natural number but decimal and fraction (see Chap. 4). Proportionality is not limited to discrete numbers but is extended to real numbers and extend. The definition of multiplication by measurement (Chap. 3) is based on proportionality.

${ }^{4}$ This interpretation of multiplication under proportionality is the only possible in Western culture. Under the influence of Euclid, Western Arithmetic is known as being ratio-proportion oriented. Eastern Arithmetic is known as being digit-calculation oriented, under the influence of the calculation matrix (table) and abacus.
} 
The forms in Margarita Philosophica did not contain contradictions. However, in this format, we can find the origin of the contradictions and confusion about multiplication in Europe, which are discussed in Chaps. 3, 4, and 6. The contradiction will appear if we add the multiplication symbol " $x$ " into the vertical form as well as the algebraic expression. If we rewrite the vertical form shown on the left in Fig. 7.6 as an expression from the top row to the bottom row, it is $7954 \times 642$ which means 7954 (as the multiplier) $\times 642$ (as the multiplicand) in the manner of the table. This contradicts the explanation given by Margarita Philosophica from the lower row to the upper row. If we rewrite the vertical form as $7954 \times 642$ and read the original method in Fig. 7.6, it is 7954 (multiplicand) [×] 642 (multiplier) which looks the same as the Japanese notation. In Margarita Philosophica, it is recommended that a large number is written in the top line and a small number is written in the lower line. Instead of using the multiplication symbol " $x$ " and reading it as "multiplied by", it uses "per (by)" or "multiple (numeral)." At that time, there was no contradiction. However, the current difficulty may have appeared in the process of reorganization with algebraic notation.

Under the Universal Mathematics by Deacartes which integrate various mathematical subjects under the algebra, algebraic notation had spread in Europe (see Fig. 3.1 of Chap. 3). Oughtred introduced the symbol " $x$ " as or algebraic notation and he never used it to represent the column method. He explained the necessity and usefulness of multiplication for logistics. In Oughtred on later 1694 Edmond Halley edition, he called numbers in multiplications by factores, products, rectangle, and plane and not mentioned multiplier or multiplicand. ${ }^{5}$ On Gilberto Clark commentary for Oughtred's Clavem mathematicam (Key of the Mathematics) in 1682, the rectangle area diagram is added and both numbers of multiplier and multiplicand in column multiplication were called by factors, It implies that to avoid the confusion between multiplier and multiplicand in vertical form and expression they might preferred their rectangle and factors. Indeed, today, the area formula is length (longer side) $\times$ width (shorter side) as well as column multiplication which locate larger number top line. Rectangle is the model to explain commutativity from the era.

In that era of Margarita Philosophica in Europe, to define multiplication, they needed proportions. On the other hand, in China, arithmetic meant various methods of the numerical calculation on situations which had more than four operations from an early stage. In ancient China, arithmetic operations were written in the Suàn Shù Shü [A Book on Numbers and Computations] (186 BCE; English translation by Cullen, 2004), a bamboo book (Dauben, 2008). The multiplication table was necessary to memorize for using rods ${ }^{6}$ on a calculation matrix which represented the base ten place value system, like the column methods. In Jiǔzhāng Suànshù [The Nine Chapters on the Mathematical Art], anonymous authors in the tenth to second

\footnotetext{
${ }^{5}$ In 1667 edition of Oughtred, there was no symbol for operation on vertical form to calculate numbers. The symbol for operations were appeared to explains the algebraic operation for the operation of letters. Thus, originally there were no operation symbols on vertical form.

${ }^{6}$ Red rods represent positive numbers and black rods represent negative numbers.
} 


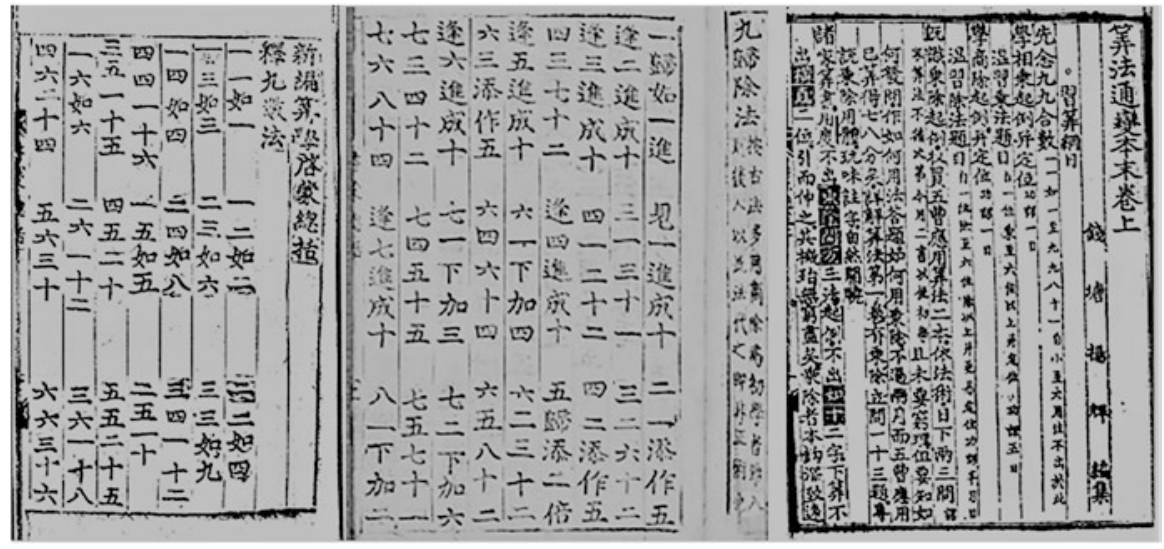

Fig. 7.7 Zhū Shìjié (1299), Suànxué Qìméng (used (元)朱世傑「新編等學啓蒙 3巻坿緆括1 巻」李朝初期) multiplication table (left) and division table (middle); and Yáng Hūi (1274, 1275) Yanghū Suan Fă (right) (used (宋)揚輝編「宋揚輝等法 7巻」慶州府, 宣徳8 [1433]). In these books, the tables are to be memorized for calculations. In the case of Suanxue Qimeng (left), the multiplication table is half and second number is constant like $1 \times 1=1,1 \times 2=2,2 \times 2=4,1 \times$ $3=3,2 \times 3=6,3 \times 3=9,1 \times 4=4, \ldots, 4 \times 4=16,1 \times 5=5, \ldots, 5 \times 5=25$ and so on. See Jinkoki on Fig. 6.8 in Chap. 6, Chap. 6 for comparison: $2 \times 2=4,2 \times 3=6,2 \times 4=8, \ldots, 3 \times 3=9,3 \times 4$ $=12$ and so on. Jinkoki's table, Fig. 6.8, is similar as Fig. 7.6 right, Margarita Philosophica but different with Suànxué Qíméng

centuries BC (10th-2nd centuries BC) had already discussed equations in a matrix. ${ }^{7}$ Later, in the Yen Dynasty, Suànxué Qǐméng (1299) began a book with a multiplication table (Fig. 7.7). It also included a division table ${ }^{8}$ which may imply that they used an abacus for calculations.

At the end of the Sòng Dynasty, Yáng Hūi asked learners to memorize a multiplication table before studying his book Yánghui Suàn Fă [Yáng Huī Algorithms] $(1274,1275)$, which is known as an introductory book (Jochi, 2003) ${ }^{9}$. This Chinese tradition was thought to have influenced the Middle East and reached Europe through Fibonacci. ${ }^{10}$

The Chinese did not necessarily invent algebraic expression itself because their calculations were well done on a matrix sheet ${ }^{11}$ up to positive and negative numbers and algebra. The Japanese extended it to solve equations using the abacus (Seki, 1674). Even during the era of Descartes in the early seventeenth century, the vertical form, not the expression, was still the major form used to represent arithmetic operations in Europe. Today, European algebraic representations have became a

\footnotetext{
${ }^{7}$ It can be seen as a kind of vertical form of the sweep-out method (thirteenth century), because it is based on the base ten system for the rod arrangement.

${ }^{8} \mathrm{~A}$ division table cannot be understood without using an abacus.

${ }^{9}$ http://www.osaka-kyoiku.ac.jp/ jochi/jochi2003b.pdf.

${ }^{10} 0$ was established in India; however, the vacant place in the calculation matrix meant 0 .

${ }^{11}$ The Chinese matrix sheet, horizontally, represents the base ten place value system, the coefficients of a polynomial, and so on; vertically it represents the process of operations.
} 
universal language for mathematics around the world. However, various vertical forms have been used in arithmetic.

Most of these forms, except those in ancient Egypt, were written vertically, using both the idea of base ten place value in columns and the multiplication table. Ancient Egypt did not use place value numerals but doubling-row 2 in the multiplication table. Here, we would like to focus on multiplication in vertical form by using the base ten place value system and the multiplication table. Under these conditions, the Egyptian method is not multiplication in vertical form. The Chinese-Japanese abacus ${ }^{12}$ has place value but the numbers are represented by beads. The abacus is a manipulative, thus the given numbers are lost in the process of manipulation and only the product remains. On the other hand, multiplication in vertical form retains the multiplier, multiplicand, and product. Vertical form is a kind of expression that preserves the relationships among the multiplier, multiplicand, and product.

Calculation on the abacus is usually done from the largest place value. In the case of multiplication of $35 \times 24$, a way of manipulation is done by the following sequence: $3 \times 2,3 \times 4,5 \times 2,5 \times 4$. If we do a calculation in this manner with an abacus, there is no contradiction between the multiplier and the multiplicand (see Chap. 3) because the order of (multiplier) $\times$ (multiplicand) never changes and their multiplication table was half which means that their table itself existed under the commutativity. Thus, the Chinese who invented the abacus did not encounter a contradiction like the European people who imported multiplication in vertical form with tables from the East, invented algebraic expression, and later, re-embedded the expression symbol " $x$ " into the column methods.

Quoted historical books usually begin with or referred the multiplication table. The multiplication table can be seen as a historical root of expression of multiplication as a binary operation. Before algebraic expression, multiplication used the table and the column. There was no necessity to explain multiplication as repeated addition because algebraic expression did not exist at that time.

\subsubsection{Revisiting the Confusion Between the Multiplier and Multiplicand, and the Need to Differentiate Them}

As explained in the historical roots, the confusion as to which one is the multiplier and which is the multiplicand in $\mathrm{a} \times \mathrm{b}$ was appeared in relation to algebraic expression. In English, "a" is the multiplier and "b" is the multiplicand. We should note

\footnotetext{
${ }^{12}$ Originally, the Chinese abacus, which used to have two five-beads on top and five one-beads for every place value in bottom, could be used for both base ten and base sixteen systems under their measurement system. The Japanese revised it into one five-bead and four one-beads as an adaptation of the base ten system for educational and industrial objective to adapt the base ten French-European unit-quantities system (see Fig. 6.8). Ministry of Education fixed Japanese-style abacus in 1935, officially. The Japanese-style abacus influenced all East Asia before World War II. Currently, it is not easy to find the original Chinese traditional style abacus in East Asia. The Chinese-Japanese abacus is a tool to support mental calculation; it is not just for counting tools like other abacuses in the world.
} 


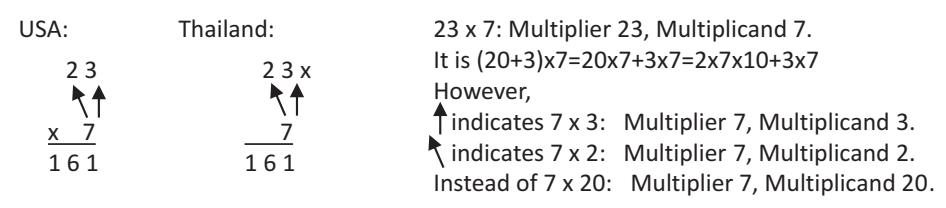

Fig. 7.8 Confusion of multiplier and multiplicand

$23 \times 7$ : Multiplier 23, Multiplicand 7.

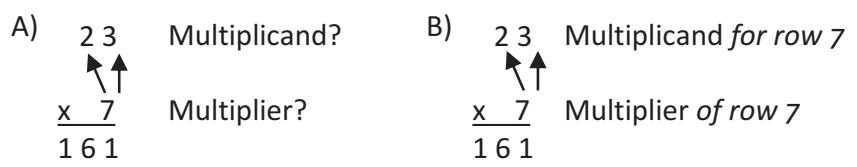

Fig. 7.9 To distinguish multiplier and multiplicand

that the algorithm in the vertical form of multiplication proceeds from the lower digits to the upper digits using a multiplication table such as in Margarita Philosophica (Fig. 7.6). In the expression " $\mathrm{a} \times \mathrm{b}$ " the first number "a" is the multiplier but "b" is usually explained as the multiplier of the row of 7 . The problem might have originated from seeing the vertical form as as for the presentation of algebraic notation expression because the historical representation does not have algebraic symbols such as " $x$ " and "="; indeed, if we put the symbol " $x$ " into the vertical form, the following contradiction will happen.

If we do not have the multiplication symbol in Fig. 7.8, it is just to support mental arithmetic. The source of confusion originated from seeing the vertical form by algebraic expression. It was identified as an overgeneralization of algebraic expression in the historical manner of arithmetic. Actually, it produces confusion even for teachers because they are likely to explain the vertical form from Margarita Philosophica as A, instead of B (Fig. 7.9).

Writing "A" is the source of confusion because 23 is the multiplier in $23 \times 7$. There are five ways to avoid this confusion: the first is to be careful of expressions like "B"; the second is to change the format of the vertical form, as in the Netherlands (Freudenthal Institute)z; the third is to change the format of multiplication, which was mentioned in Fig. 3.11 (Model A) in Chap. 3; the fourth is to change the names such as the naming of the first number (factor) and the second number (factor) instead of "multiplier" and "multiplicand," and the fifth way is to enhance commutativity. In Table 2.3 in Chap. 2, Chile, Mexico, Portugal, Singapore, and the USA (but not Brazil and Japan) do not use the terms "multiplier" and "multiplicand" (to avoid confusion) and just call them factors which do not imply the order of the two numbers.

In the case of factors with enhancing commutativity, there is no order in the expression. If students do not pay attention to the difference between the multiplier and multiplicand in situations, the students may lose the meaning of multiplication, as to which number is the unit (later it become the base for rate) and which number is the number of units. Students do not pay attention regarding the difference between 5 candies for each dish and 3 dishes, or 3 candies for each dish and 5 
dishes. They also cannot distinguish situations of division as partitive division or quotative division (see Chap. 4). As we discussed in Fig. 4.20, they cannot produce the correspondence of meanings in both divisional situations as different interpretations of multiplication, multipliers, and multiplicands in situations. And at the later grade, "for each dish" becomes "per dish" which is a necessary terminology as for the bases of ratio and rate.

\subsubsection{Terminology for Teaching Column Multiplication}

Multiplication in vertical form is not repeated addition. For clear understanding, here we would like to confirm some basic technical terms for multiplication in vertical form, considering various approaches depending on the country. ${ }^{13}$

Mental Arithmetic Mental arithmetic is done by calculating mentally using memorized arithmetic. For vertical forms of addition and subtraction, it is necessary to memorize composition and decomposition of numbers for making 10 which is necessary for carrying and borrowing by place values. For multiplication in vertical form it is also necessary to memorize the multiplication table. In the diversity of vertical forms (Fig. 7.1) the Chilean method needs more mental arithmetic than those of Japan and the Netherlands.

Mental arithmetic is a necessary part of number sense to devise numbers and operations judiciously. For example, if students recognize 4 times in comparing 25 and 100, they have a sense of the quadruple. In the Japanese approach, the relationship between two expressions such as $80 \times 2.4$ and $80 \times 24$ (see Fig. 4.18 in Chap. 4) are formally learned as a part of number sense. ${ }^{14}$

Multiplication Table In relation to a numeral system such as in English, a multiplication table sometimes includes numerals up to 12 or more, depending on the country and culture. In the case of Spanish, the numerals up to 15 have specific names, then from 16 onward they are written as dieciséis ("ten and six"), etc., but after 100, the numbering in Spanish is well configured as the base ten system. On

\footnotetext{
${ }^{13}$ The terminologies in English for teaching elementary school mathematics were locally systematized by various scholars such as Treffers, Nooteboom, and de Goeij (2001) and Reys, Lindquist, Lambdin, and Smith (2012). The Freudenthal Institute provides the necessary ideas to describe the learning trajectory (see van den Heuvel-Panhuizen, 2001). Clements \& Sarama (2004) defined learning trajectory by three aspects: a learning goal, developmental progressions of thinking and learning, and a sequence of instructional tasks. However, these terminologies are not unified around the world under the teaching culture which teachers prefer their own work sheets for teaching (see Sect. 4.4, Chap. 4). Terminology for elementary school mathematics teaching also exists in Japan (Isoda and Nakamura, 2010) and it is more precise in the shared curriculum sequence as explained in Chap. 4.

${ }^{14}$ In Japan, this has been formally enhanced, as an objective from the 1998 curriculum, as one of the ways to think about how to calculate, and the think about how to calculate based on the number sense are necessary for the bases of symbol sense in junior high school in the 2009 curriculum. Symbol sense was discussed by Abraham Arcavi (1994).
} 
the other hand, many Spanish-speaking countries use multiplication tables up to 9. This implies that those countries may have more difficulty engaging in multiplication as mental arithmetic. The French numeral system is also complicated.

In some countries such as Singapore, memorization is explained as development of number sense or proficiency in operations. In some countries such as Mexico and Chile, advanced students are able to use their partially memorized table with possible strategies to find the answer in multiplication.

Standard or Formal Algorithm An algorithm ${ }^{15}$ is a fixed sequential step-by-step calculation or procedure which usually includes recursive process. The terms "standardized algorithm" or "formal algorithm" in vertical form can be fixed in every country but are not necessarily the same as those in other countries because there is no universal format likely algebraic expression (see Fig. 7.1). The Japanese curriculum asks students to think the ways of calculation. ${ }^{16}$ In the case of vertical form, it means selecting the standard algorithm in comparison with other possible approaches and appreciating every idea, especially the reasonableness of the standard algorithm. In Japanese textbooks, an algorithm similar to the Netherlands one (Freudenthal Institute) also appeared as a student's idea before the Japanese standard algorithm was set. Here, "formal" and "informal" are relative because the likely Netherlands algorithm also appeared in Japanese textbooks as a student's idea. In classroom, students ideas can be seen as informal ideas however on the Japanese textbooks such possible ideas are formally treated. Japanese teachers are expected to treat them as ways of meaningful calculation in the process to select simpler, faster and easier one (see Chap. 1 Mindset, Table 1.1 in Chap. 1).

Decomposition Decomposing a number with base ten by using the distributive law enables students to consider the way of multiplication beyond the multiplication table. Before the introduction of column multiplication, the known product of multiplication was within the table. If we multiply by 10 times (bai in Japanese), it is easier to find the product of multiplication by 20 times, 30 times, and so on. In 20 [ $\times] 3$ (20, 3 times), if we decompose the multiplication, it is $2 \times 10 \times 3=2 \times 3 \times 10$. Decomposing numbers with base ten by using the distributive law such as $23 \times 7=20 \times 7+3 \times 7$ is a key idea to produce column multiplication to distinguish

\footnotetext{
${ }^{15}$ In relation to developing the competency for coding and computational thinking (National Research Council, 2011; Araya, Isoda, Rafael, Inprasitha, To appear), finding and creating the algorithm itself enhances the objective of multiplication in vertical form.

${ }^{16}$ In Japan, as well as understanding of the meaning and acquisition of the skill, thinking about ways of calculation, or thinking about how to calculate, which asks students to consider various ways of calculation, is a key objective. It includes a variety of vertical forms. It was introduced in the 1998 reforms. In the newest Japanese curriculum (MEXT, 2017a, 2017b), it is explained as follows. (1) Teachers should help students: (a) to understand that multiplication of 2- and 3-digit numbers by 1 - and 2-digit numbers is based on basic multiplication of 1-digit numbers, and to understand how to calculate, using algorithms in a column form; (b) to multiply accurately and to use multiplication appropriately; and (c) to understand simple properties that hold for multiplication. (2) Teachers should help students to acquire the following abilities of thinking, making decisions, and expressing: (a) focusing on mathematical relations, thinking about ways of calculation; (b) exploring properties that hold for calculations; and (c) calculating simply and checking the result of a calculation by making use of the properties.
} 
tens and ones using the row of 7 in the multiplication table. In Chap. 3, splitting as another usage (Figs. 3.6 and 3.7) is a representation of the distributive law and originally meant dividing equally (Fig. 3.4). In Fig. 7.1, the Japanese and the Netherlands vertical forms for multiplication clearly use decomposition which requires addition of an intermediate process for multiplication in vertical form. However, the Chilean vertical form requires mental arithmetic for the intermediate addition part and is not clear on how students do the intermediate part. Teachers may have to teach it through giving exercises. The Japanese approach enables students to think about how to calculate the intermediate addition part at first, and later this part will be reduced in relation to the progress in mental arithmetic.

\subsection{Lesson Study for Introducing Multiplication in Vertical Form}

As discussed at Fig. 1.1 in Chap. 1, for the extension of multiplication, students have to reintegrate multiplication table with base ten place value system by using decomposition of numbers, opposite direction of distribution, instead of repeated addition. Even though the distributive law itself will be learned later, Gakko Tosho textbooks already introduced the idea at the second grade as for the extension of multiplication table (see Fig. 6.3, Chap. 6). Here, the way a Japanese teacher introduces multiplication in vertical form for Grade 3 students, especially how to introduce the idea of decomposing with the distributive law, is illustrated with the full format of the lesson plan, as follows. The first steps are to watch the video for understanding of the lesson and then to show the whole lesson plan to share how it was carefully prepared in the case of school-based lesson study for developing students in Japan. The first part is intended to illustrate decomposition of numbers to prepare for multiplication in vertical form. It is an exemplar showing how Japanese students produce their ideas, some of which are necessary for further learning based on what they have already learned. The second part is detailed in the next section as an Annex for explaining schoolbased lesson study with the full format of the lesson plan which includes a unit plan for introducing multiplication in vertical form beyond repeated addition.

\subsubsection{Lesson Study Video Introducing Vertical Form}

This lesson was taught based on the 1998 curriculum by Mr. Hideyuki Muramoto, with the assistance of Prof. Kazuyoshi Okubo (Muramoto and Okubo, 2007), in the third grade, on the topic of multiplication algorithms. It was video recorded for the Asia-Pacific Economic Cooperation (APEC) project "Innovations in the Classroom Through Lesson Study" (Isoda, Shimizu, Loipha, and Inprasitha, 2007). ${ }^{17}$ The list of

\footnotetext{
${ }^{17}$ Report retrieved on June 29, 2019, from http://www.criced.tsukuba.ac.jp/math/apec/apec2007/ progress_report/; video of Mr. Muramoto's class and lesson plan retrieved on June 29, 2019, from http://www.criced.tsukuba.ac.jp/math/apec/apec2007/index.html\#video.
} 


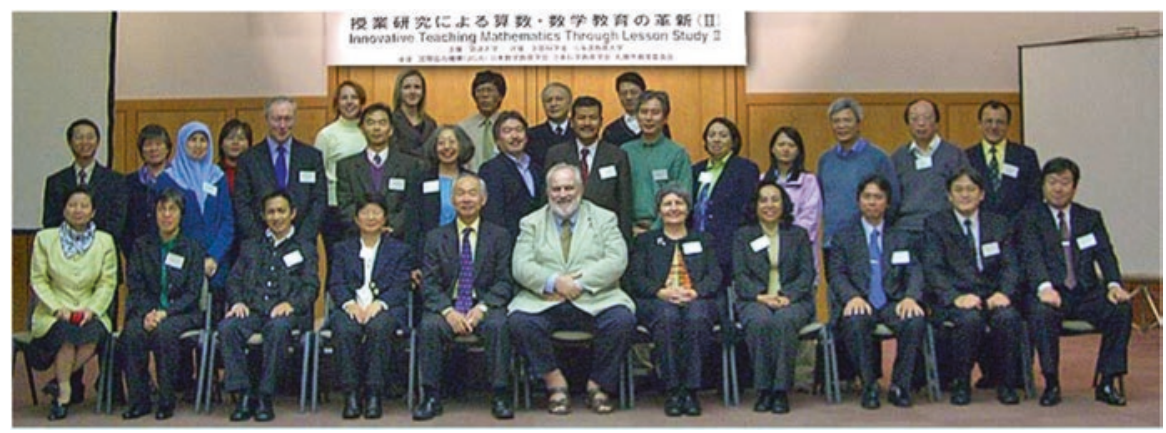

Fig. 7.10 Participants in the Asia-Pacific Economic Cooperation (APEC) Lesson Study Project for 2007 who observed Mr. Muramoto class

episodes and clips was developed by David Tall (Tall, 2013), and video can be seen too at the following URL: https://youtu.be/7tG_UDbQnmo.

The lesson is an example of the lesson study process for teaching mathematics. This 50-minute research lesson was planned and taught at Maruyama Primary School in Sapporo, Japan, to a grade 3 class of 40 students. It is the fourth class in a sequence of 13 sessions (see the last part of the next section). The task sequence in the 13 sessions begins from $20 \times 3$ which can be solved by repeated addition, and is then extended to $23 \times 3$ which is not easy to solve by repeated addition but is easy to solve by decomposition under the base ten place value system..$^{18}$ Finally, decomposition is used in multiplication in vertical form, followed by exercises. The fourth class discussed $23 \times 3$, which participants observed (Figs. 7.10 and 7.11).

The previous lesson considered the product of $20 \times 3$ and encouraged students to calculate the number of black circles (marbles) in the arrangement shown in Fig. 7.12, ${ }^{19}$ where the total of (10, 3 times) plus (10, 3 times) is $30+30$, which is 60 .

The detailed lesson plan can be found in the next section. Please note that the array diagrams used here can be read in two directions. As discussed in Fig. 4.9 in Chap. 4, the diagram does not consider the order of operation.

In this lesson, the students are encouraged to use their learned knowledge to solve the problem of calculating how many circles there are in a new arrangement (in which they will find 23, 3 times). The plan is to find various ways of doing it and consider which ones are more complicated and which ones are easier. The longterm goal is to make the students aware of the advantages of constructing column

\footnotetext{
${ }^{18}$ About Japanese task sequence for extension and integration principle, please see Chap. 1 and Chap. 4 such as Fig. 4.10 for the introduction of decomposition and composition of numbers and making 10, and Fig. 4.27 for task sequence for viable arguments by extension. Extension and Integration principle is a key principle for "Construct viable arguments and critique the reasoning of others." (CCSS.MATH, 2010).

${ }^{19}$ This is the diagram for decomposing multiplication. For learning vertical form, Japanese teachers enable students to use the diagram and never use concrete objects for this task because concrete objects merely enhance counting which is not multiplication.
} 


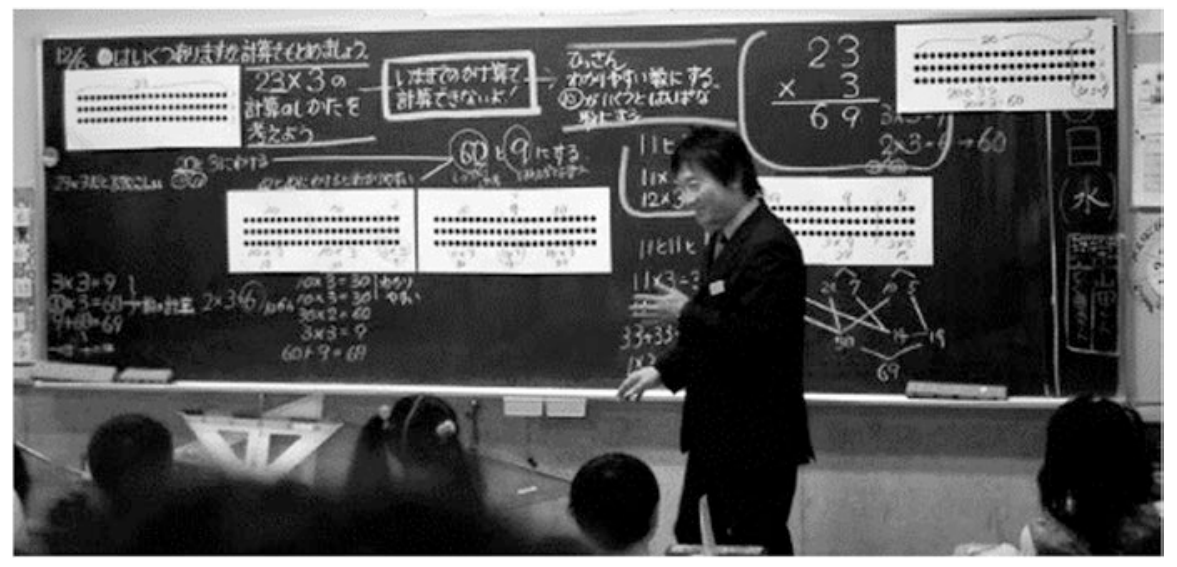

Fig. 7.11 The summary part of the lesson study by Mr. Muramoto

Fig. 7.12 A diagram for $20 \times 3(20,3$ times $)$

Fig. 7.13 Which one among the decompositions is better?
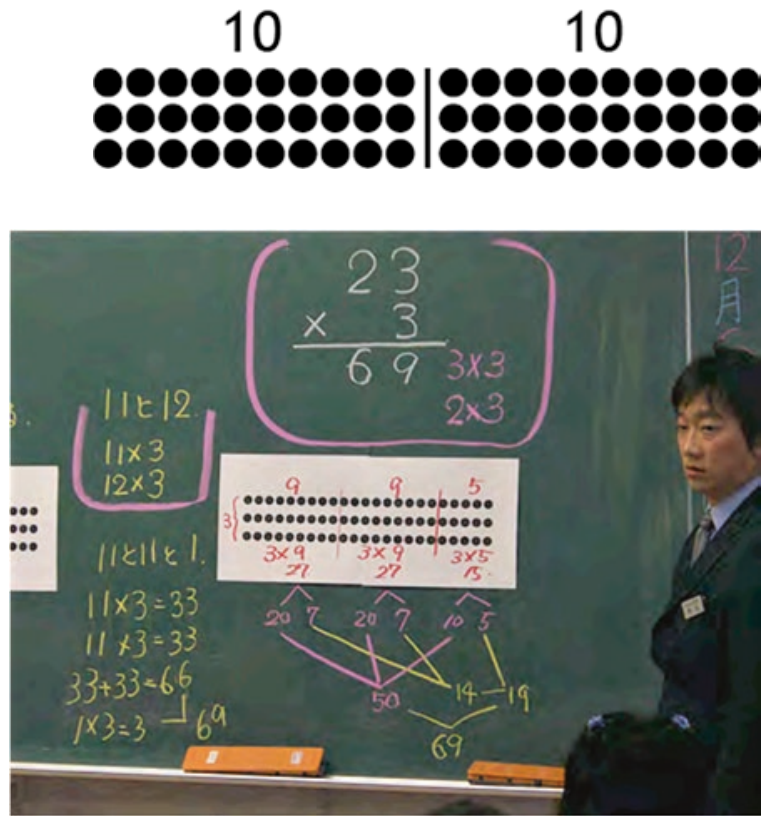

multiplication through a meaningful experience related to practical examples (Fig. 7.13).

When watching the video, take note of how the teacher begins at the left side of the chalkboard with the problem, prepares the development of the lesson, and indicates important points in yellow chalk so the structure of the entire lesson is visible on the chalkboard. 
The objective of this lesson is to help the students think about how to multiply 2-digit numbers by 1-digit numbers. ${ }^{20}$ As soon as they see the mathematical expression (that is, $23 \times 3$ ), many of them feel that the problem cannot be solved directly using the multiplication table. If the students can see the structure of the problem with an arrangement (split) diagram, they will realize they can calculate this problem using the results of the multiplication they have already learned. "I want to make sure the students can see that they can use the idea of how many times a quantity contains the unit quantity," ${ }^{21}$ Mr. Muramoto indicates.

In this lesson, the students will decompose the 2-digit numbers that are easy to use with the multiplication table. Through this investigation, the students will carry out the decomposition of a 2-digit number into various ways to make the calculation possible. Finally, based on simplicity, decomposition by tens and units (that is, 23 into 20 and 3 ) is preferred to use for the vertical form. Additionally, they will learn that this idea is the foundation of the multiplication algorithm (the method for calculating with pencil and paper).

The crucial point of this lesson is that the students consider the way of calculation by themselves. They investigate the ways to decompose the number 23 so they can use what ever they have already learned. For example, students learned to set various groups as for the unit to study the every row of multiplication. To understand the algorithm, it is necessary that the students recognize the significance of decomposing 23 into 20 and 3 such as simplicity. In this lesson, the teacher wants the students to observe a diagram in order to decompose the 2-digit number for use of the multiplication table.

In the following description, the teacher's intention for this class, the actual teaching phases for the class, and the teacher assessment views are illustrated to provide the minimum knowledge needed to follow the video. The precise information for understanding the theme of the lesson study is provided in the next section as an Annex based on Mr. Muramoto's lesson plan.

\subsubsection{Mr. Muramoto's Objectives for This Class}

At the start of the postclass discussion, after the class observation, Mr. Muramoto restates his purpose as follows:

Since the beginning of the school year (April), I have taught the students to draw a diagram of the problem situation in order to think about how to deduce expression and calculate. Also, I have emphasized the importance of mathematical learning in class, so the students can use the diagram to explain their logical thinking processes.

\footnotetext{
20 "Think about how to calculate" is a key objective of teaching operations in the Japanese national curriculum standards, as well as understanding of the meaning and acquisition of skill (see footnote 1). With this objective, Japanese teachers do not just try to make sense by putting the meaning into students but provide preparations for sense making that students may make sense of by and for themselves, by using their learned knowledge (see Chap. 5).

${ }^{21}$ This is the definition of multiplication by measurement (see Chap. 3).
} 
There are some students in the class who already know how to multiply using the algorithm. Even though they already know the algorithm, it is not clear if they really understand its meaning. The students can understand it by looking at the diagram. They recognize the meaning and the value of decomposing the 2-digit number to calculate and generalizing the idea of "how many times a certain quantity contains the unit quantity."

The solution to the problem $23 \times 3$ is always 69 , independently of how the number 23 is decomposed to make the calculation. The students will realize how diverse ideas for making the calculation can be used, learning from each other in the classroom.

Doubtful students or those who have difficulty with 2-digit multiplication may not be able to grasp the idea of decomposing the 2-digit number, and instead they might use addition $(23+$ $23+23=69$ ). By learning from each other in the classroom and presenting various ideas, they can begin to think, "If I decompose 23 , I wonder if the calculation would be easier."

A diagram that shows how the number 23 is decomposed in various ways and the mathematical expressions that go along with each different method will help these students to compare ideas and think of a better method.

This is his commentary after the class. The observers observe the class with a lesson plan. The lesson plan will be explained later. The illustration of the real class activity shows how the students are able to think of decomposing the number for multiplication in vertical form instead of repeated addition. The original lesson plan for school-based lesson study is too long and is shown in the next section.

\subsubsection{Description of Actual Lesson Episodes}

The lesson plan by the teacher, Mr. Muramoto, can be found in the Annex. The following table describes the seven principal episodes of the lesson, which were produced by David Tall. The total lesson video was retrieved on June 30, 2019, from https://youtu.be/7tG_UDbQnmo.

\begin{tabular}{|c|c|}
\hline $\begin{array}{l}\text { Description of the content of each of the principal episodes of the } \\
\text { class (available in the videos) }\end{array}$ & $\begin{array}{l}\text { Identification of the } \\
\text { episodes in a video clip }\end{array}$ \\
\hline $\begin{array}{l}\text { In this class, Mr. Muramoto introduces a new problem, and the } \\
\text { students try to guess what it is, based on their prior experience. The } \\
\text { problem is presented in the video clip, and at the end, the students } \\
\text { wait for a copy of the problem to calculate } \\
\text { Video at https://youtu.be/tolkfvBbDRM }\end{array}$ & $\begin{array}{l}\text { The problem } \\
\text { (Video } 1 \text { of } 7 \text { ) } \\
\text { Begins at } 01: 58 \\
\text { duration } 1: 20\end{array}$ \\
\hline $\begin{array}{l}\text { After establishing the problem of calculating } 23 \times 3 \text {, Mr. Muramoto } \\
\text { encourages the students to work on their own, then he walks around the } \\
\text { classroom while they work for about } 5 \text { minutes. He takes note of who } \\
\text { has finished and who has not, then invites the students to explain their } \\
\text { ideas. Initially, all the ideas are related to decomposing } 23 \text { into } 20 \text { plus } \\
3 \text {, or into } 10 \text { plus } 10 \text { plus } 3 \text {. The video clip shows the first answer } \\
\text { Video at https://youtu.be/Qk6gJRIw9rY }\end{array}$ & $\begin{array}{l}\text { The student Amon sees } \\
23 \text { as } 20+3 \\
\text { (Video } 2 \text { of } 7 \text { ) } \\
\text { Begins at } 16: 45 \text {, } \\
\text { duration } 2: 18\end{array}$ \\
\hline
\end{tabular}




\begin{tabular}{|c|c|}
\hline $\begin{array}{l}\text { Description of the content of each of the principal episodes of the } \\
\text { class (available in the videos) }\end{array}$ & $\begin{array}{l}\text { Identification of the } \\
\text { episodes in a video clip }\end{array}$ \\
\hline $\begin{array}{l}\text { Each answer is received with approval, except possibly that of one } \\
\text { student, who sees the entire arrangement as } 30+30+9 \text {; he has seen } \\
\text { the whole problem as two subarrangements of } 3 \text { rows of } 10 \text {, which is } \\
30 \text {, and a subarrangement of } 3 \text { rows of } 3 \text {, which is } 9 . \text { The teacher } \\
\text { explains to him calmly that he has not yet finished and must write it } \\
\text { down in his notebook } \\
\text { Video at https://youtu.be/Di2xz4hoJgk }\end{array}$ & $\begin{array}{l}\text { Amano has not finished } \\
\text { (Video } 3 \text { of } 7 \text { ) } \\
\text { Begins at } 21: 56 \\
\text { duration } 1: 01\end{array}$ \\
\hline $\begin{array}{l}\text { One answer suggests that the } 2 \text { in } 23 \text { can be considered as two } 10 \text {-yen } \\
\text { coins } \\
\text { Video at https://youtu.be/ef_5eHYv4nI }\end{array}$ & $\begin{array}{l}\text { Using } 10 \text {-yen coins } \\
\text { (Video } 4 \text { of } 7 \text { ) } \\
\text { Begins at } 25: 18 \\
\text { duration } 2: 00\end{array}$ \\
\hline $\begin{array}{l}\text { After about } 17 \text { minutes dedicated to the examples of decomposing } 23 \\
\text { into } 20 \text { and } 3 \text {-or into } 10,10 \text {, and } 3 \text { - a student suggests that no one } \\
\text { has proposed anything different } \\
\text { Video at https://youtu.be/a6IUrFlynL8 }\end{array}$ & $\begin{array}{l}\text { "I realized something" } \\
\text { (Video } 5 \text { of } 7 \text { ) } \\
\text { Begins at } 33: 53 \\
\text { duration } 1: 02\end{array}$ \\
\hline $\begin{array}{l}\text { After this intervention, various possibilities come up, including } \\
11+12,9+9+5 \text {, and } 11+11+1 \text {. The teacher encourages the } \\
\text { students to talk among themselves. The video shows the difficulty of } \\
\text { decomposing it as } 9+9+5 \\
\text { Video at https://youtu.be/Qk6gJRIw9rY }\end{array}$ & $\begin{array}{l}3 \times 9,3 \times 9,3 \times 5 \\
(\text { Video } 6 \text { of } 7) \\
\text { Begins at } 38: 13 \\
\text { duration } 2: 15\end{array}$ \\
\hline $\begin{array}{l}\text { The teacher finds that some students have used the standard vertical } \\
\text { form for presenting the problem. In the video, he encourages one of } \\
\text { them to explain his idea. Then, he connects the vertical form to the } \\
\text { other methods using posters and puts up a poster of the vertical sum } \\
\text { for direct comparison. After the episode is shown, there is a detailed } \\
\text { 5-minute session that summarizes the class, in which Mr. Muramoto } \\
\text { gets the students to read the purpose of the class from the chalkboard } \\
\text { and suggest phrases to describe the class. The entire chalkboard } \\
\text { presents the lesson's principal ideas from left to right, allowing the } \\
\text { students to consider the whole discussion and make their own notes } \\
\text { Video at https://youtu.be/i0m_K9wqJXE }\end{array}$ & $\begin{array}{l}\text { Vertical form } \\
\text { (Video } 7 \text { of } 7 \text { ) } \\
\text { Begins at } 42: 08, \\
\text { duration } 4: 02\end{array}$ \\
\hline
\end{tabular}

The previous table shows seven episodes. The following table refers to the identification of a 40-episode sequence. Each episode is associated with a position in the sequence, a duration, a name that identifies it (as well as an introduction to the problem, class activity, discussion, and summary), and a brief reference to the content of the episode.

Multiplication algorithm for the third grade. Teacher: Mr. Hideyuki Muramoto

December 6, 2006; 1:35-2:20 p.m.; Maruyama Elementary School, Sapporo

\begin{tabular}{l|l|l}
\hline Time & Length & Episode \\
\hline $00: 15.8$ & $01: 35.6$ & $\begin{array}{l}\text { Introduction }[8 \mathrm{~min}, 36 \mathrm{~s}] \\
\text { The teacher begins by writing down the problem for the students to copy in } \\
\text { their notebooks. Note that the students know the format: a problem is } \\
\text { presented on the chalkboard and they wait for a photocopy to do the } \\
\text { calculations themselves }\end{array}$ \\
\hline
\end{tabular}




\begin{tabular}{|c|c|c|}
\hline 02:21.6 & 01:28.1 & $\begin{array}{l}\text { The problem } \\
\text { How many circles are there? } \\
\text { Showing the circles row by row, the students guess how many there are (often } \\
\text { based on the previous class with } 20 \text { circles in each row, before realizing that } \\
\text { now there are 23) }\end{array}$ \\
\hline $03: 19.5$ & 01:56.9 & Handing out the photocopies \\
\hline 05:16.4 & 00:06.6 & Finding the answer by calculating (adding or counting) \\
\hline 05:23.0 & 00:27.3 & 23 circles \\
\hline 05:50.3 & 00:22.4 & How many are there in the top row? \\
\hline $06: 12.7$ & 02:40.6 & And in the next row? \\
\hline 08:53.3 & 00:38.6 & $\begin{array}{l}\text { Lesson activity [ } 5 \mathrm{~min}, 13 \mathrm{~s}] \\
\text { Think about how to calculate } 23 \times 3\end{array}$ \\
\hline 09:31.9 & 04:34.6 & [Lesson activity] \\
\hline 14:06.5 & 01:48.3 & $\begin{array}{l}\text { Discussion [first half: } 17 \mathrm{~min}, 39 \mathrm{~s} \text { ] } \\
\text { The teacher begins the discussion by suggesting that they cannot calculate } \\
23 \times 3 \text { using the ideas they have already learned }\end{array}$ \\
\hline $16: 44.9$ & 00:50.3 & $\begin{array}{l}\text { Who has written it down? The teacher first checks who among the students } \\
\text { have written an answer, who knows how to do it, and who still doesn't have } \\
\text { any idea }\end{array}$ \\
\hline 19:04.2 & $02: 19.2$ & $\begin{array}{l}\text { The student Amon decomposes } 23 \text { as } 20+3 \text {. The teacher writes } 3 \times 3=9 \text {, } \\
20 \times 3=60,9+6=69 \text {, corrected (as observed below) to } 9+60=69\end{array}$ \\
\hline 19:51.5 & 00:47.3 & $23 \times 3$ is complicated. Shinjo presents the same idea \\
\hline 20:41.0 & $00: 49.5$ & $\begin{array}{l}\text { My idea might be the same. Another girl does the same thing; } 3 \times 3 \text { is } 9 \text { and } \\
20 \times 3 \text { is } 6 \text { (corrected to } 60 \text { ) }\end{array}$ \\
\hline $21: 24.7$ & 00:43.7 & $\begin{array}{l}\text { I use what we have learned. Another girl explains how she has used what she } \\
\text { learned from the previous lesson }\end{array}$ \\
\hline $21: 40.7$ & 00:31.2 & Tens and units. The girl explains in terms of units places and tens places \\
\hline $21: 56.9$ & $01: 10.5$ & $\begin{array}{l}\text { Amano has not finished. (Amano sees the arrangement as } 9,30,30 . \text { The } \\
\text { teacher speaks softly to him and does not make it public) }\end{array}$ \\
\hline 23:06.4 & 02:12.1 & $\begin{array}{l}\text { Chiba is similar to Amano but makes an error. He decomposes } 23 \text { into } 20 \text { and } \\
3 \text {, multiplies } 3 \times 3 \text {, and adds } 20 \text {, obtaining } 29 \text {. Other students discuss }\end{array}$ \\
\hline $25: 18.5$ & $25: 18.5$ & $\begin{array}{l}\text { Using } 10 \text {-yen coins, they once again decompose } 23 \text { into } 20 \text { and } 3 \text {, but now } \\
\text { they explain } 20 \text { as two } 10 \text {-yen coins, so } 2 \times 3 \text { is } 6\end{array}$ \\
\hline $27: 19.2$ & 01:34.2 & $\begin{array}{l}2 \text { groups of } 10 \text {, one of one (the teacher divides the poster into rows of } 10,10 \text {, } \\
\text { and } 3 \text {, and writes what the students have explained): } 10 \times 3=30,10 \times 3=30 \text {, } \\
30 \times 2=60,3 \times 3=9,60+9=69\end{array}$ \\
\hline 28:53.4 & 00:34.1 & $\begin{array}{l}\text { Tell me why. (Another boy explains how easy it is to make groups of } 10 . \text { The } \\
\text { book says that) }\end{array}$ \\
\hline 29:27.5 & 01:21.6 & Who has the same idea? (Another student gives a similar explanation) \\
\hline 30:49.1 & 00:56.4 & $20 \times 3$ is easier. I know something. Multiplication by 10 is easier \\
\hline $31: 45.5$ & $01: 42.4$ & $\begin{array}{l}\text { Another method }[14 \mathrm{~min}, 27 \mathrm{~s}] \\
\text { A boy suggests a new distribution, decomposing } 23 \text { into } 10+3+10 \text { with } \\
3 \times 3 \text { in the middle. There are surprised whispers in the classroom }\end{array}$ \\
\hline $33: 27.9$ & 00:25.3 & $\begin{array}{l}\text { Now use } 10 \text { and } 5 \text {. A girl returns to yesterday's calculations of } 20 \times 3 \text { which } \\
\text { are still displayed at the side }\end{array}$ \\
\hline $33: 53.2$ & 01:02.6 & $\begin{array}{l}\text { I noticed something. A student suggests that all the methods end with } 60 \text { and } \\
9 ; \text { none calculated } 39 \text { and } 30\end{array}$ \\
\hline $34: 55.8$ & $00: 54.6$ & $\begin{array}{l}23 \times 3 \text { is complicated. As we said before, } 23 \times 3 \text { is very complicated and } \\
\text { confusing. We have learned to calculate } 20 \times 3 \text {, numbers that end in zero }\end{array}$ \\
\hline
\end{tabular}




\begin{tabular}{|c|c|c|}
\hline 35:50.4 & 01:01.1 & $\begin{array}{l}23 \times 3 \text { does not end in zero. A boy explains that this is why we decomposed } \\
23 \text { into } 20 \text { and } 3 \text { or } 10,10 \text {, and } 3\end{array}$ \\
\hline $36: 51.5$ & 00:07.9 & $\begin{array}{l}\text { A different way? The teacher asks if anyone has decomposed it in a different } \\
\text { way }\end{array}$ \\
\hline 36:59.4 & $01: 13.6$ & $\begin{array}{l}11+12 \text {. A boy says he decomposed } 23 \text { into } 11 \text { and } 12 \text { to calculate } 11 \times 3 \text { and } \\
12 \times 3 \text {. The teacher says, "We haven't studied that yet." The students talk } \\
\text { about the difficulty of that }\end{array}$ \\
\hline 38:13.0 & 02:18.1 & $\begin{array}{l}3 \times 9,3 \times 9,3 \times 5 \text {. The teacher writes the students' calculations on the } \\
\text { chalkboard in a complex manner. The teacher approves and asks if they are } \\
\text { similar to the other calculations. }\end{array}$ \\
\hline $40: 31.1$ & $01: 37.3$ & $\begin{array}{l}23 \text { is } 11,11 \text {, and } 1 . \text { A boy makes a calculation with a small error, which is } \\
\text { corrected }\end{array}$ \\
\hline 42:08.4 & 01:37.4 & $\begin{array}{l}\text { Vertical form. The teacher notices that Mai writes the problem in vertical } \\
\text { form using the standard algorithm. He asks her to share her idea. There is } \\
\text { discussion about tens and units, with some use of the idea of } 10 \text {-yen coins }\end{array}$ \\
\hline 43:45.8 & 01:43.6 & $\begin{array}{l}\text { Is it totally different? Yamada talks about the relationship between the poster } \\
\text { and the calculation that } 3 \times 3 \text { is } 9 \text { and } 3 \times 20 \text { is } 60 \text {. In particular, he focuses on } \\
3 \times 2 \text {, which is } 3 \times 20 \text { with the answer in the tens place. The teacher explains } \\
\text { it in terms of } 10 \text {-yen coins }\end{array}$ \\
\hline $45: 29.4$ & $00: 43.5$ & $\begin{array}{l}\text { Watching carefully. The teacher takes the paper with calculations using } \\
\text { vertical rows of circles }\end{array}$ \\
\hline $46: 12.9$ & 00:07.2 & $\begin{array}{l}\text { Summary [ } 5 \mathrm{~min}] \\
\text { The time runs out. A boy says, "I want to do more!" }\end{array}$ \\
\hline $46: 20.1$ & 02:08.3 & $\begin{array}{l}\text { Any good ideas? Takashi thinks it is good to think of two } 10 \text {-yen coins. He } \\
\text { explains that some people use numbers like } 60 \text { and add numbers that are not } \\
\text { round numbers (in the units place)—round numbers that end in zero. Tsubota } \\
\text { expands the idea }\end{array}$ \\
\hline 48:28.4 & 00:23.8 & $\begin{array}{l}\text { Let's read. The teacher asks the students to read what they have written on the } \\
\text { chalkboard. "We thought about how to calculate } 23 \times 3 \text { " }\end{array}$ \\
\hline 48:52.2 & 02:20.4 & $\begin{array}{l}\text { What should we write? The teacher encourages the students to say what to } \\
\text { write. He takes the phrase "the vertical calculation form" and writes a phrase } \\
\text { selected from the students' suggestions to end the class }\end{array}$ \\
\hline $50: 36.5$ & $01: 35.6$ & End and credits \\
\hline
\end{tabular}

For watching the video, please note the questions for formative assessment, written in the lesson plan (and listed in the next section), which will provide focal points.

\subsubsection{Criteria for Formative Assessment in the Lesson Plan}

The lesson plan, which is explained in the next section, plans to promote the students' capacity for logical explanation. The teacher plans to pay attention to the following points and help the students to recognize them individually and as a class.

- Do the students use diagrams to understand the problem situation?

- Can students show their own thinking using diagrams? 
- Can they reflect on, justify, and analyze their thinking using diagrams?

- Can they express their thinking or thought process using words like "because," "as such," "for example," "if . . ., then . ..," and "while . . , then . .."?

- What point of view do the students have for comparing various ideas?

- How different are their answers?

- How different are their expressions?

- What are the reasons behind their thinking?

- How much do they use prior knowledge?

- Can they recognize the value of comparing different ideas and appreciate the new questions that result from this comparison?

- Can they relate their knowledge to the problem being discussed?

These explanations support the content in the video for establishment of decomposition of numbers to prepare for multiplication in vertical form beyond repeated addition.

The video illustrates well how Mr. Muramoto's students actively participate in and contribute to the lesson by and for themselves. His deep consideration to develop students is explained in his original lesson plan in the next section.

\subsection{Annex for Sect. 7.2: Excerpts of the Lesson Plan by Mr. Muramoto, Illustrating Why and How a Japanese Teacher Prepares School-Based Lesson Study}

The previous exemplar with the video is an ordinary Japanese method to initiate multiplication in vertical form. It is the subtheme of this book. The subtheme explains the Japanese approach with the various theories behind lesson study which is mentioned Chap. 1. For lesson study, Japanese teachers usually have a research (study) theme and an objective for the lesson (Isoda, 2015a, 2015b), as discussed in Chaps. 1 and 5. The objective of the lesson is written for the specified teaching content in the curriculum sequence. The research theme is usually related to higherorder thinking skills such as mathematical thinking, values, and attitudes. In Japan, these are written as the general aim in the mathematics curriculum such as development of mathematical thinking and appreciation of simplicity. There are various Japanese theories ${ }^{22}$ behind this, such as mathematical thinking for making clear the objectives of the teaching materials such as value, attitude, mathematical ideas and

\footnotetext{
${ }^{22}$ The Japanese theory for mathematics education has been oriented toward designing mathematics class for developing children who learn mathematics by and for themselves, and trying to explain, specify, and share the objectives and aims of every class; they also function as the assessment standards for teaching. The theory is used for designing mathematics classes to carefully recognize the aims of mathematics education in every lesson and its task, and how well embedded the aims are into every lesson and task sequence over several lessons in every teacher's planned curriculum. When compared with other countries, major differences can be seen in the curriculum and task sequences which have been prepared for enabling students to learn value and ways of thinking, and so on. The sequence is prepared to support extension and integration, which means reorganization of learned knowledge for extended situations (Chap. 1).
} 
ways of thinking (Isoda, 2012, 2016; Managao, Ahmad, \& Isoda 2017), and theories to establish the task sequence to set the opportunity for students to think by and for themselves.

In Japan, school-based lesson study (see Chap. 1, Fig. 1.5; and Chap. 5, footnote 13) is usually done for research and development in the school on the setting and targets of the school and under the subject groups under theoretical discussion. It clarify the comprehensive objectives of their mathematics teaching in the school. If non-Japanese teachers just observe the video, they may recognize some differences in the teaching methods from the activities of teachers and students. If they try to copy the activities as a method of teaching, they may experience difficulty and attribute this to cultural differences and so on. Such impressions may come from overlooking and missing perspectives such as the teaching materials with clear objectives, the established task sequence for the unit level, and the long-term sequence for human character formation. The Japanese approach is a cultural practice based on the theories behind these perspectives (Chap. 1). ${ }^{23}$ Here, to illustrate how lesson study is carefully planned, excerpts from Mr. Muramoto's lesson plan as a part of schoolbased lesson study are presented. ${ }^{24}$ The research theme of the school, the lesson study group and the teacher, and part of the lesson plans will be presented in the following order: the school and lesson study group vision in the setting of the school in relation to the research (study) theme, the unit plan with its objective, and the lesson plan ${ }^{25}$ with its objective and assessments. The followings sited in small fonts are half of the excerpts from the original documents provided by Mr. Muramoto as for school-based lesson study. Here, the term "we" means his lesson study group at Maruyama Elementary School. In the followings, small font sentences are quotations or resume from his complete-specification lesson plan and normal fonts are commentaries.

\subsubsection{Maruyama Elementary School Mathematics Group Vision and Mathematics Lesson Study Group's Goals}

Japanese lesson study is oriented toward the aims and objectives of education in the curriculum. Mr. Muramoto explains his school's lesson study vision as follows:

\footnotetext{
${ }^{23}$ It is not just a method of teaching that can be alternate other methods because it is proffered to realize the specified objective.

${ }^{24}$ As explained at Fig. 1.4 in Chap. 1, school-based lesson study is managed by the research department at every school. Subject-based lesson study is usually managed by teachers' societies for specified subjects/disciplines. National- or regional-level lesson study is usually supported by laboratory schools affiliated with universities. The subject-based and national levels lead the national curriculum reform and the establishment of theories for designing the school curriculum with known theories. Here, this is school-based lesson study and discusses a school mathematics curriculum. The Japanese aims of education are discussed in Chap. 1.

${ }^{25}$ In the school-based lesson study approach (konaikenkyu in Japanese), which produces a learning community of teachers under the leadership of the principal, the description given in this section is necessary as part of the lesson plan for the school-based lesson study.
} 
The mathematics group's goals are those of elementary mathematics from the first grade through the sixth grade; that is:

- To establish learning with clear and systematic connections throughout the learning content

- To help children to acquire basic knowledge and technical skills regarding numbers, quantities, and geometric figures through mathematical activities; to promote the capacity for creative and logical thinking; and to promote the attitude of enjoying the activity and appreciating the value of mathematical manipulation, and its use in daily life ${ }^{26}$

\subsubsection{Actual Setting of the Students in Maruyama}

When we, the mathematics lesson study group, analyzed the students' scores on the achievement test in our school, we found that our students were above the national average in every domain in elementary school mathematics, although the drop in student achievement in the international context has become a topic of discussion in Japan.

\subsubsection{Research Theme for Lesson Study}

What kind of lessons develop students who can use what they have learned before to solve problems in new learning situations by making connections? For this question, preparation of teaching materials is the key.

\subsubsection{Focal Points for Kyozaikenkyu (Preparation of Teaching Materials According to the Objective/Research on the Subject Matter) for Implementation of the Research Theme}

We think that encouraging problem solving through mathematical activities will help us to reach this goal.

We think that teachers need greater clarity about how the topics of study are connected to one another. We need to think about how students can use previously learned content to solve problems in new situations and how different problem-solving situations require various forms of prior learning, and we need to use these ideas in the development of units and lessons.

To help the students to be responsible for their own problem-solving process, we think that students should be more aware of their own problem-solving processes and be able to articulate how they have made connections to prior learning and how they have used the ideas to solve problems in new situations.

Students acquire the capacity to think about their own diagrams and the number line, reflecting on their own problem-solving processes, determining what they understand and what they do not, and comparing their solutions with those of their classmates.

We think that students should not only focus on the accuracy or inaccuracy of their answers but also reflect on their own problem-solving processes. They have to understand that it is important to feel the genuine enjoyment of learning mathematics as well as getting correct or incorrect answers.

\footnotetext{
${ }^{26}$ See Chap. 1.
} 


\subsubsection{Thinking About Assessments That Help Students to Be More Precise in Their Problem-Solving Processes}

We need to think about what points to pay attention to in assessing students' learning in the teaching process in order to help them develop the mathematical thinking that is necessary to carry out meaningful and effective problem-solving activities (see Sect. 7.2.4).

\subsubsection{Support for Other Teachers in School to Improve Students' Learning}

In school-based lesson study, teachers work as a team. The mathematics lesson study group in school also supports other teachers. Mr. Muramoto describes this as follows:

We will administer tests to understand the current state of student learning. Giving tests not only is a way to understand the current state of learning but also can be useful if teachers use them to reflect on and improve their own teaching.

\subsubsection{Necessary Communication with Other Teachers}

We share our essential approach with other teachers by demonstrating it through an open class. For example, it is important to encourage students to express themselves mathematically on what they have learned from each other in the classroom. Some examples of the capacities we want to develop are:

- To be able to describe ideas using number lines and diagrams

- To be able to manipulate concrete materials and explain their ideas to others

- To be able to think about and understand the meanings of numbers and operations, expressing them in mathematical expressions

- To be able to take notes that reflect students' thinking and points of view

It is necessary for the mathematics group to engage in good communication with other groups in the school. Our assessment and vision of teaching and learning in the classroom is discussed because all staff members in the school can provide a consistent and systematic approach in educating our students as a whole.

\subsubsection{To Promote Human Character Formation with Strong Hearts and Minds, Students Who Acquire This Kind of Competency Can Participate in the Classroom in the Following Ways}

In the Japanese national curriculum standards, mathematics is a subject for human character formation, as well as other subjects. In relation to the theme of the lesson study, Mr. Muramoto and his study group teachers describe the subject as the progressive development of logical thinking, as discussed in the following sections. 


\subsubsection{Planning Consistent Development of Proficiency in Logical Thinking}

At the end of the second grade, students begin to use expressions like "because . . ." to describe their reasons and support their ideas.

In the third grade, they begin to compare their own ideas with those of others, and the expressions they use are "My idea is similar to that idea, so ..."

In the fourth grade, students use expressions like "for example . .." and "because ...." more frequently. Also, they begin to use hypothetical declarations like "If this is so, then ..."

In the fifth grade, they can be more sophisticated in their statements-for example, "If this is . . ., then it will be . . , but if it is . . , then I think we can say ..." under certain conditions.

Finally, in the sixth grade, students can begin to describe things like "It can be said that this is so, but in the situation . . . . . . is much better" and begin to make decisions about how to choose a better idea.

We hope to see this capacity of expressing oneself mathematically more often in the classroom, and, as such, we would like to examine the current state of student learning more carefully.

We believe that feelings and emotions need to be incorporated into students' learning. The feelings and emotions we refer to here are the students' hopes and desires, as well as their feelings and emotions that are derived from their particularities, all of which are necessary for students to autonomously and actively involve themselves in their own learning. This includes feelings and emotions expressed through phrases like "I wonder why . ..," "If that's so, then ...," "Is this always true?" and "There, I found it!"

These are some of the things we hope for and are trying to achieve. We believe that knowledge is gained through feelings and emotions, and that these will really help students to acquire solid capabilities and strong hearts and minds.

\subsubsection{Survey of Students for Preparation and Challenges}

In the School Based Lesson Study, teachers usually survey current status of their students for knowing reform direction, improvements and progress:

We carried out a survey about mathematics learning among third-grade students at Mayurama Elementary School for preparing lessons, and the responses were as follows:

Do you like mathematics?

- 50\%: yes

- 44\%: sometimes yes

- 5\%: sometimes no

- $1 \%$ : no

The students who answered "Yes":

- I like calculations and enjoy them.

- Yes, I understand, it's entertaining.

- Because the answers are clear.

- Because I can listen to various ideas.

The students who answered "Sometimes yes":

- I like calculations but not problems.

- It is very difficult to construct mathematical expressions for the problems. 
The students who answered "Sometimes no" or "No":

- I don't like problems.

- The tests are difficult.

- It is very difficult to construct mathematical expressions.

Maruyama's Elementary School third-grade students like calculations, but many of them feel they are not good at constructing mathematical expressions for the problems. Thus, the following ideas are used to develop units and lessons:

We would like to increase the number of students who think logically and provide them with the capacities they need to understand the structures of the problems using diagrams and the number line.

We would like to increase the number of students who are interested in listening to other students' problem-solving processes, thinking about whether the problem-solving process is similar or different, and being able to communicate it.

\subsubsection{Exploring Topics That Students Learn in the Third Grade}

The topics that students learn are the following:

- Addition and subtraction (3-digit numbers in vertical form)

- Multiplication (2- and 3-digit numbers multiplied by a 1-digit number using the algorithm)

- Division (its meanings and remainders)

- Large numbers (up to 10 million)

- Time and duration (meaning)

- Volume, length, and weight

- Characteristics of rectangles and squares

- Box forms (characteristics and nets)

- Tables and bar graphs (categorized data and construction of tables and bar graphs)

The key mathematical ideas and thinking that students learn in almost all domains of thirdgrade mathematics are to think about quantities in terms of how many times the unit of measurement is contained in the quantity. ${ }^{27}$

- In addition, subtraction, and large numbers, we take $1,10,100$, etc., as the unit.

- In multiplication and division, we look at how many times a quantity contains the unit of measurement, and we look at dividing something by a number of units.

- In time and duration, volume, length, and weight, we see how many times something contains the unit of measurement.

Using the big mathematical idea of how many times a quantity contains the unit quantity as the governing principle, we develop lessons that help to emphasize this idea, as well as thinking of daily lessons that will help to nourish this idea. For example:

- We develop lessons that help students to be aware of the connection between what they have learned before and what they are learning now, and to use previously learned knowledge to overcome obstacles in a new situation.

\footnotetext{
${ }^{27}$ This is the definition of multiplication by measurement (Chap. 3).
} 
- We representing a problem situation with diagrams based on the idea of how many times a quantity contains the unit quantity consistently, helping students to understand the situation and the solution with greater clarity, and developing lessons that incorporate this idea to help them use the diagram to think logically about the solution to the problem.

- We develop lessons that help students to understand what they need to compare in various ideas, previous ideas, and representations such as diagrams.

These students' understanding will be enriched through lessons that pay attention to the problem-solving process in which prior knowledge is used.

\subsubsection{Challenging Issues for the Lesson Study Group with Viewpoints}

Although the achievement of students at Maruyama Elementary School appears to be good, we recognize that there are many students who wait to receive instructions from teachers about how to solve the problems instead of doing that by themselves.

We do not think there are many students who indicate a strong desire to address challenging problems, saying, "I want to solve this problem on my own, even if it takes me a long time." Also, there are not many students who enjoy solving problems by trial and error.

We think this is the result of lessons that have not provided pleasant experiences in which the students reach solutions on their own, see interesting regularities or patterns in their investigations, think about this, and share questions that come up during learning with their classmates.

To develop students who can enjoy learning mathematics and acquire capacities for logical reasoning, which are the aims of the national curriculum standards, we decided to develop lessons with three viewpoints.

These viewpoints are discussed in the following.

\subsubsection{Viewpoint 1: Teaching Material to Connect Unknown Content with Learned content}

To develop teaching materials that pay attention to the connections between previously learned content and new content

It is necessary to clarify the mathematical thinking that the students have learned in the 6 years of primary school, by researching teaching materials and the students' processes of development. To do so, one must understand how previously learned content is necessary for learning new content, and how useful it is.

What students learned about multiplication in the second grade is precisely useful for calculation. The idea they learned regarding "how many times the unit of measurement a quantity is" is a fundamental idea of mathematics.

Also, in the second grade the students learn "length" by direct comparison, indirect comparison, and measurement with arbitrary units. So, the students who recognize the necessity of measuring with a universal unit can learn "weight" in the third grade using similar thinking.

The students who think about the "why" of the problem-solving process can begin to make connections between the problem and what they need to think about it, as well as what they need to think. 


\subsubsection{Viewpoint 2: Knowing the Significance of Own Ideas Through Comparison with Others' Understanding}

Students can learn from each other and this helps them to think conscientiously about their own problem-solving processes.

There are many new things students can learn from each other in the classroom when they experience the real value of mathematics, its beauty, and its importance.

- Students can clarify their own problem-solving processes and participate in discussions to learn from each other.

- Students can learn through discovery by comparing their own thinking with that of others.

- Students can reflect and evaluate what they understand and what they do not.

- Students can clarify how they solve problems.

Learning experiences in the classroom that promote learning from each other not only improve student learning but also develop strong bonds among students.

\subsubsection{Viewpoint 3: Prepare the Task Sequence with Formative Assessments}

Assessment that promotes students' capacity for logical thinking

For the students to be capable of thinking logically, we think they need to clarify their own problem-solving processes when they are doing problem-solving activities.

First, so that students enrich their learning, we think it is very important that the teacher provides help in organizing the chalkboard and highlighting the lesson's important points.

Second, we want to plan appropriate help so that students feel the need to think about what prior knowledge they need to remember and can make connections to the new problem situation. Also, we want to include support questions to encourage students to think deeply about their problem-solving processes, understand each idea they produce (including the similarities and differences of these ideas), and expand the knowledge they can gain through working together.

Finally, we want to prepare a second problem that helps us to understand student learning during the lesson to support understanding of the effect of what students learn from each other in the lessons.

Considering the current state of learning of Maruyama's students and the content of the topic, we think it is important to develop units and lessons with these viewpoints in order to achieve the overall goal of developing students who can use what they have learned previously to solve problems in new learning situations by making connections.

\subsubsection{Unit and Lesson Plans}

The teachers intend to carry out:

- Lessons that prepare students to think conscientiously about the connection between what they have learned before and what they are leaning now

- Lessons in which students learn from each other and that help them to think conscientiously about their own problem-solving processes

- An assessment that helps to strengthen students' capacities for logical thinking 
The specific unit goals are:

- To think about how to calculate the multiplication of 2- and 3-digit numbers by 1-digit numbers using the ideas about multiplication that have been learned previously (calculations with 2- and 3-digit numbers multiplied by 1-digit numbers using the idea of decomposing numbers in the base ten system)

- To be able to carry out the calculation of 2- and 3-digit numbers multiplied by 1-digit numbers using the algorithm

The content that the students learned before this unit includes:

- Multiplication of 1-digit by 1-digit numbers (second grade)

- Multiplication that involves zero, multiplying by tens (third grade)

- Using the idea of the distributive law of multiplication to create the multiplication table (for example, the multiplication table of 7 can be developed using the tables of 5 and 2)

The lesson topic is:

- Third-grade mathematics lessons that promote students' capacity to use what they have previously learned and make connections for solving problems in new learning situations

The lesson learning goal is:

- To be able to think about how to carry out the calculation of a 2-digit number multiplied by a 1-digit number using what was previously learned about multiplication (mathematical thinking)

\section{Unit Plan for 13 Sessions}

\begin{tabular}{|c|c|}
\hline & Learning activities \\
\hline 1 & $\begin{array}{l}\text { Let's find out by calculating! } \\
\text { Because we have } 3 \text { groups of } 20 \text { circles, I wonder if we can use multiplication. To } \\
\text { calculate } 203 \text { or } 20+20+20,20 \text { is two tens. We can discover how many tens there } \\
\text { are using } 2 \times 3\end{array}$ \\
\hline 2 & $\begin{array}{l}\text { Let's think about the statement of the problem that shows the mathematical expression } \\
20 \times 3 \\
\text { "Each chocolate costs } 20 \text { yen. We buy three. What is the total price?" }\end{array}$ \\
\hline 3 & $\begin{array}{l}\text { If the price of an item is } 300 \text { yen, what is the mathematical expression? } 300 \times 3 \\
\text { This time we can think about how many groups of } 100 \text { there are. We can discover how } \\
\text { many hundreds there are using } 3 \times 5\end{array}$ \\
\hline 4 & $\begin{array}{l}\text { Let's find out by calculating! } \\
\text { This time a group has } 23 \text { circles. There are approximately } 60 \text { circles } \\
\text { The mathematical expression should be } 23 \times 3 \text {. We cannot calculate it easily using the } \\
\text { multiplication table. If we decompose } 23 \text { into smaller parts, then we could use the } \\
\text { multiplication table. We can use an algorithm (a method of calculating with paper and } \\
\text { pencil) to calculate. } 9 \times 3,9 \times 3,5 \times 3 \text {, together is } 69.10 \times 3 \text {, } 10 \times 3,3 \times 3 \text {, together is } \\
69.20 \times 3,3 \times 3 \text {, together is } 69 \text {. Which of these ideas is easiest to calculate? They all } \\
\text { decompose } 23 \text { into smaller parts }\end{array}$ \\
\hline
\end{tabular}




\begin{tabular}{|c|c|c|}
\hline & Learning activities & \\
\hline 5 & $\begin{array}{l}\text { Let's find out how to calculate using the algorithm (a method of calculating with } \\
\text { paper and pencil). Think of } 23 \text { as } 20 \text { and } 3 \text {. Put } 3 \times 3 \text { and } 20 \times 3 \text { together. } \\
\text { Calculate using the multiplication table }\end{array}$ & $\begin{array}{l}23 \\
\times 3 \\
69\end{array}$ \\
\hline 6 & \multicolumn{2}{|l|}{$\begin{array}{l}\text { How many } \bullet \text { are there? Let's find out by calculating! The mathematical expression is } \\
16 \times 4 \text {. It should be greater than } 40 \text {. It looks like it is greater than } 40 \text {. We can make this } \\
\text { calculation by decomposing } 16 \text { into } 10 \text { and } 6 \text { like we did before. Let's make this } \\
\text { calculation using the algorithm. } 6 \times 4=24 \text {. We cannot write } 24 \text { in the units place. I } \\
\text { wonder how I should write the number } \ldots \text { We can write the } 2 \text { in } 24 \text { in the tens place }\end{array}$} \\
\hline 7 & \multicolumn{2}{|l|}{$\begin{array}{l}\text { Let's do a bunch of problems like } \bullet \bullet \times \cdot \text { ! Let's think about all the problems using the } \\
\text { algorithm. Some of the answers give } 3 \text {-digit numbers. There are answers where } 0 \\
\text { appears in the tens place. There are problems that imply regrouping twice }\end{array}$} \\
\hline 8 & \multicolumn{2}{|l|}{$\begin{array}{l}\text { The price of a meter of ribbon is } 312 \text { yen. We buy } 3 \text { meters of ribbon. How much does } \\
\text { the ribbon cost? What would an estimate for the answer be? It should be more than } 900 \\
\text { yen. The mathematical expression is } 312 \times 3 \text {. I wonder if I can use the algorithm again } \\
\text { for this. . If we decompose } 312 \text { into smaller numbers, we can calculate } \ldots 300 \times 3 \text {, } \\
10 \times 3,2 \times 3 \text {, together is } 936\end{array}$} \\
\hline & \multicolumn{2}{|l|}{$\begin{array}{l}\text { Let's do some problems like } \bullet \bullet \times \bullet ! \text { I do a problem in which the answer is a 4-digit } \\
\text { number. I do a problem that implies regrouping }\end{array}$} \\
\hline 10 & \multicolumn{2}{|l|}{ Let's practice calculating with the algorithm! } \\
\hline 11 & \multicolumn{2}{|l|}{$\begin{array}{l}\text { We can begin to calculate however we want. The price of a cake is } 60 \text { yen. There are } \\
\text { four cakes in each box. If we buy two boxes, what will the total price be? I think we will } \\
\text { need two mathematical expressions to solve this problem. First, we find the price of a } \\
\text { box. } 60 \times 4=240 \text {. We have two } 240 \text {-yen boxes; } 240 \times 2=480 \text {. First, we find the total } \\
\text { number of cakes; } 4 \times 2=8 \text {. A cake costs } 60 \text { yen, so } 60 \times 8=480\end{array}$} \\
\hline 12 & \multicolumn{2}{|l|}{ Let’s practice! } \\
\hline & \multicolumn{2}{|l|}{ Let's review what we have learned in this unit } \\
\hline
\end{tabular}

\section{Lesson Plan}

\begin{tabular}{l|l}
\hline $\begin{array}{l}\text { Learning activities and anticipated student } \\
\text { reactions and thoughts }\end{array}$ & Points to consider \\
\hline $\begin{array}{l}\text { How many are there? } \\
\text { Let's find out by calculating! }\end{array}$ & $\begin{array}{l}\text { To understand the task, help students to see } \\
\text { the circles as "how many in a group" and } \\
\text { "how many groups" }\end{array}$ \\
$\begin{array}{l}\text { There are } 23 \text { circles in each row } \\
\text { There are } 3 \text { groups of } 23 \text { circles }\end{array}$ & $\begin{array}{l}\text { Before calculating, encourage students to } \\
\text { estimate the answer }\end{array}$ \\
$\begin{array}{l}\text { I wonder if we could use what we have already } 60 \text { circles. We can discover } \\
\text { learned about multiplication. The mathematical } \\
\text { expression should be } 23 \times 3\end{array}$ & \\
\hline $\begin{array}{l}\text { We cannot simply use the multiplication table to } \\
\text { make the calculation. What should we do? }\end{array}$ & $\begin{array}{l}\text { Praise them when they remember what they } \\
\text { have already learned. Try to understand the } \\
\text { students' various ideas by walking around the } \\
\text { classroom }\end{array}$ \\
\hline
\end{tabular}




\begin{tabular}{|c|c|}
\hline $\begin{array}{l}\text { Learning activities and anticipated student } \\
\text { reactions and thoughts }\end{array}$ & Points to consider \\
\hline 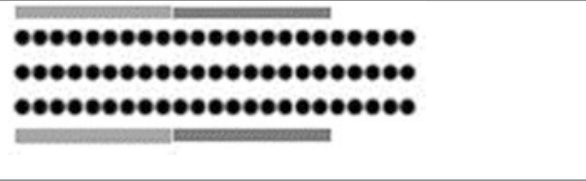 & $\begin{array}{l}\text { When you encounter students solving the } \\
\text { problem using addition, ask them "Can you } \\
\text { use multiplication to make this calculation?" } \\
\text { Make sure you use the diagrams to represent } \\
\text { how the calculations were carried out }\end{array}$ \\
\hline $\begin{array}{l}\text { S1: } \\
\quad \text { Decompose } 23 \text { into } 9,9 \text {, and } 5 \\
\quad 9 \times 3=27,9 \times 3=27,5 \times 3=15 \\
27+27+15=69 ; 69 \text { circles } \\
\text { S2: } \\
\quad \text { Decompose } 23 \text { into } 10,10 \text {, and } 3 \\
\quad 10 \times 3=30,10 \times 3=30,3 \times 3=9 \\
\quad 30+30+9=69 ; 69 \text { circles } \\
\text { S3: } \\
\quad \text { Decompose } 23 \text { into } 20 \text { and } 3 \\
\quad 20 \times 3=60,3 \times 3=9,60+9=69 ; 69 \text { circles }\end{array}$ & $\begin{array}{l}\text { Make sure you encourage students to share } \\
\text { their various ideas and help them to make a } \\
\text { conscious effort to make their own value } \\
\text { judgment regarding the various ideas. If a } \\
\text { student uses an algorithm to calculate, ask } \\
\text { him or her to think about how this calculation } \\
\text { method is related to the diagram }\end{array}$ \\
\hline $\begin{array}{l}\text { If we decompose } 23 \text { into smaller parts, we can } \\
\text { use different multiplications from the } \\
\text { multiplication table to make the calculations. } \\
\text { Which of these do you think is a good idea? } \\
\text { What similarities are there among the different } \\
\text { solutions? All the methods decide to decompose } \\
23 \text { into smaller parts. There are methods that } \\
\text { imply decomposing } 23 \text { into } 3 \text { parts and into } 2 \\
\text { parts. The numbers used in the mathematical } \\
\text { expressions are different. If we use the } \\
\text { multiplication } 20 \times 3 \text { that we learned before, we } \\
\text { have two mathematical phrases. I use an } \\
\text { algorithm (calculating with paper and pencil) to } \\
\text { make the calculation } 23 \times 3 \text {. If we compare this } \\
\text { method and the diagram, this method also } \\
\text { decomposes } 23 \text { into } 20 \text { and } 3 \text {. If we decompose } \\
\text { a number into smaller parts, then we can use the } \\
\text { multiplication table, making the calculation in } \\
\text { today's problem. The idea we use in the } \\
\text { algorithm (calculating with paper and pencil) is } \\
\text { similar to the idea of decomposing } 23 \text { into } 20 \\
\text { ( } 2 \text { in the tens place) and } 3 \text { ( } 3 \text { in the units place) }\end{array}$ & $\begin{array}{l}\text { Make sure you highlight the idea of "making } \\
\text { the calculation easier using the multiplication } \\
\text { table and other ways of multiplying that we } \\
\text { have already learned." if a student uses the } \\
\text { algorithm, help him or her to consciously } \\
\text { connect the idea of the algorithm to this idea }\end{array}$ \\
\hline
\end{tabular}

From the excepts of Mr. Muramoto's full-speck lesson plan, it is clear that the lesson plan is not written for illustrating the methods of teaching for copying; instead, it is written for answering why and what questions, such as why we need teaching materials and what teaching materials are needed for the specified students. If we share why, we can develop teaching materials with appropriate task sequences and clear objectives. These are the theories behind the explanation of the teaching activities in the Japanese problem-solving approach. It is not a method of teaching but a method to achieve the objectives with well-configured and sequenced teaching materials (see Chap. 1). What is necessary for the approach is a set of objectives and teaching materials that can be defined by the content and the task sequence with the aims and the objectives. 


\subsection{Multidigit Multiplication in Vertical Form: Task Sequence for Extension and Integration in the Case of Gakko Tosho}

The previous section illustrates how a Japanese teacher introduces multiplication in vertical form with the example of $23 \times 3$. In this section, the task sequence (see Chap. 4) of multidigit multiplication after learning multiplication of a 2-digit number by a 1-digit number is illustrated to explain how Japanese teachers develop students who are able to extend their ideas by and for themselves by using what they have already learned.

In this section, the Gakko Tosho textbooks Study with Your Friends: Mathematics are referred to because these have been preferred and used in Thailand, ${ }^{28}$ Mexico, ${ }^{29}$ Indonesia, ${ }^{30}$ and Papua New Guinea ${ }^{31}$ on well-configured task sequences for extension and integration. This is the outstanding feature of the Gakko Tosho edition. The following sections include excerpts from a Gakko Tosho textbook for illustration of task sequences to explain the manner of extension and integration by students. Every task has an exercise for proficiency, but that is not described here.

\subsubsection{Task Sequence for Extension}

In the Gakko Tosho textbooks (Isoda and Murata, 2011; Hitotsumatsu, 2005), multidigit multiplication introduced Grade 3 in the following.

\footnotetext{
${ }^{28}$ This is the Open Approach Project by Maitree Inprasitha. By using the Thai edition of the Gakko Tosho textbook (Inprasitha and Isoda, 2010), he and his colleagues in Thailand produced a number of research articles under the name Open Approach such as in the Psychology of Mathematics Education (PME) and others. Their reteaches follows the Gakko Tosho textbook sequence under the Japanese national curriculum; it is called the problem-solving approach in Japan. When the Japanese say "open approach" this implies that the class is working with open-ended tasks (see Nohoda's open approach in Chapter 1). With regard to the task for the problem-solving approach defined by the task sequence in the textbooks in relation to the objectives under the unit plan in the curriculum, it is not necessarily the task should be an open-ended task; however, it produces various solutions like an open-ended task because it is posed as an unknown task for students in the task sequence. within students' reach (zone of proximal development (ZPD), Vygotsky, 1962). Students can challenge as long as they well learned the previous tasks under the curriculum and textbooks.

${ }^{29}$ The Pre-service Teacher Education Project for all teacher education colleges under the Ministry of Education, Mexico, by Marcela Santillan Nieto and Tenoch Cedillo Ávalos (Isoda and Cedillo, 2012).

${ }^{30}$ The Curriculum Center Project by the Ministry of Education, Indonesia (ongoing).

${ }^{31}$ The Japan International Cooperation Agency (JICA) Improving the Quality of Mathematics and Science Education (QUIS-ME) project by the Department of Education, Papua New Guinea (ongoing).
} 


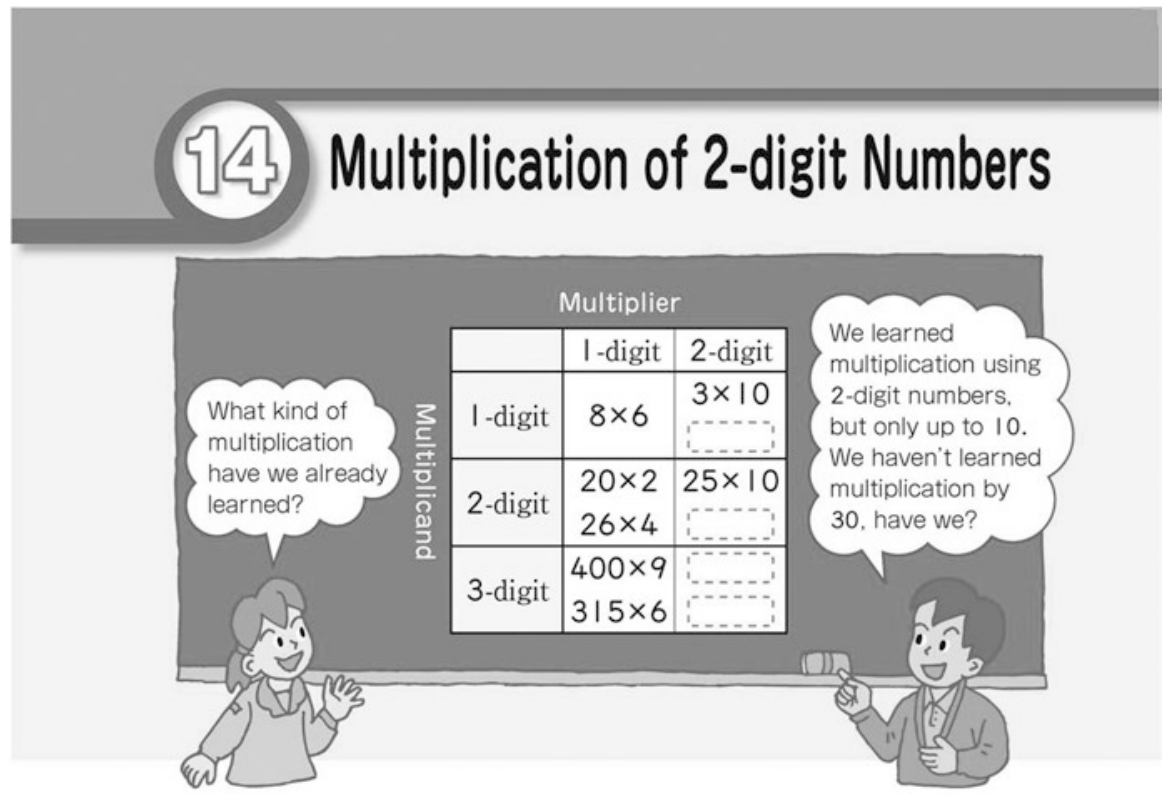

Fig. 7.14 Gakko Tosho (Hitotsumatsu, 2005), Grade 3, Vol. 2, p. 59; and Gakko Tosho (Isoda, Murata, 2011), Grade 3, Vol. 2, p. 63

\subsubsection{Task 1: Extension by Students}

In this task (Fig. 7.14), a teacher provides a two-dimensional table with empty boxies, and asks students to fill in examples and discuss what they have learned (such as when and how they learned it, and what they have not yet learned. In Fig. 7.14, there are the empty boxes indicate things they have not yet learned. The other filled expressions indicate things the students have already learned when they studied multiplication in vertical form at Grades $2 \& 3$. From this contrast, students recognize the necessity to extend the numbers for multiplication in vertical form to multidigit numbers. Some of the leading teachers ask students to plan and discuss their learning sequence too. ${ }^{32}$

\subsubsection{Task 2: $4 \times 30$}

The textbook provides an opportunity for thinking about how to calculate, which has been an aim in the national curriculum standards since 1999, as well as comprehensive understanding and fluency of operation. To meet this objective, the task sequence is established by the extension and integration principle (see Chap. 1).

\footnotetext{
${ }^{32}$ The Japanese approach oriented to develop students by and for themselves. Thus, leading teachers of Lesson Study usually demonstrate their ways to develop students to learn mathematics by and for themselves.
} 


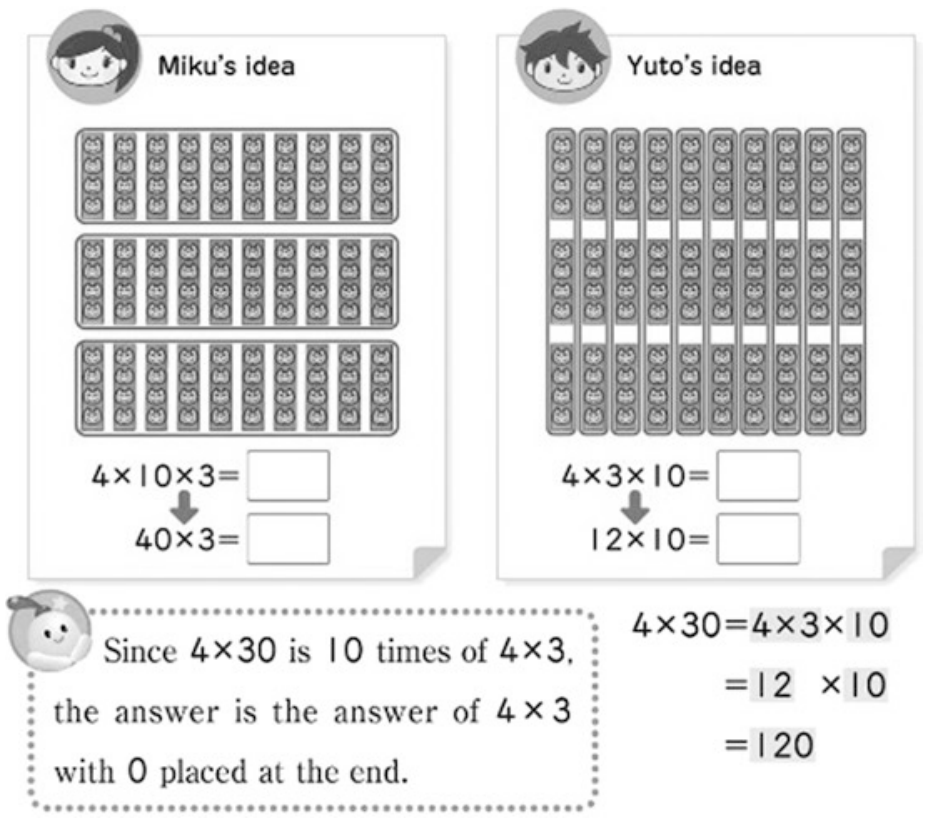

Fig. 7.15 Gakko Tosho (Hitotsumatsu, 2005), Grade 3, Vol. 2, p. 60; and Gakko Tosho (Isoda, Murata, 2011), Grade 3, Vol. 2, p. 64

At Grade 2, in Fig. 7.15, the task 2 for Grade 3 can be solved using groups of groups, 10 times. At Grade 2, students already learned T0 $\times$ U. The associativity of multiplication has already been learned (see Chap. 6).

\subsubsection{Task 3: $21 \times 13$}

Task 3 (Fig. 7.16) is a case without carrying. It is extended with carrying as shown in Fig. 7.17.

\subsubsection{Tasks 4 and 5: With Carrying and with 0}

In the case of these tasks (Fig. 7.17), students also use block diagrams to be able to explain to others; however, they are never expected to use manipulatives because manipulatives usually provide the opportunity for counting. From the early stages such as grades 1 and 2, students should be developed to be able to draw the diagrams. The task sequence continues on to multiplication of 3-digit numbers such as $123 \times 32$ and $385 \times 35$. The last task is $508 \times 40$ which needs to consider the treatment of 0 . 

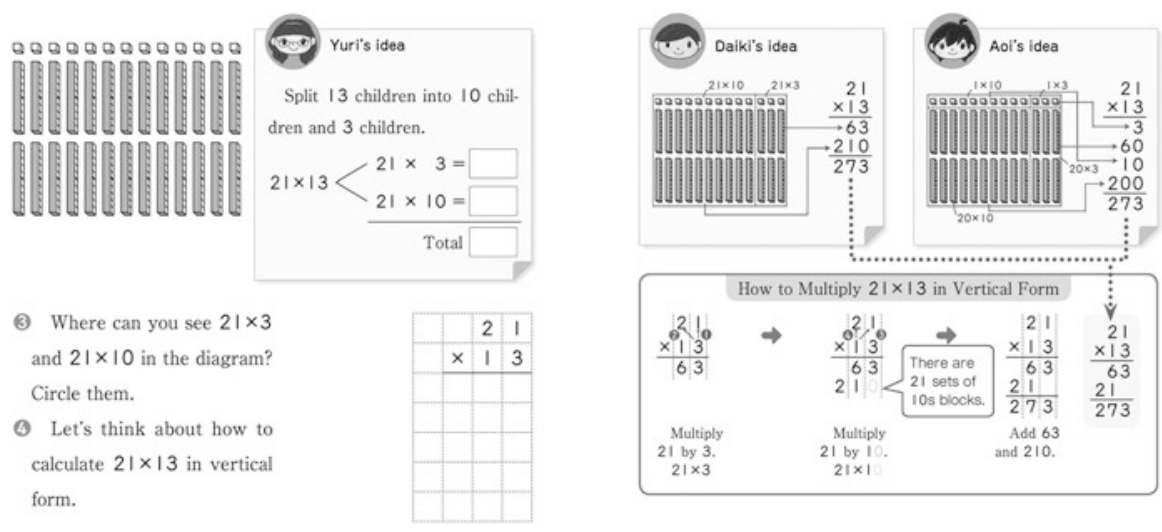

Fig. 7.16 Gakko Tosho (Hitotsumatsu, 2005), Grade 3, Vol. 2, pp. 61-62; and Gakko Tosho (Isoda, Murata, 2011), Grade 3, Vol. 2, pp. 65-66

3 Let's think about how to multiply in vertical form.

\section{(1) $58 \times 46$}

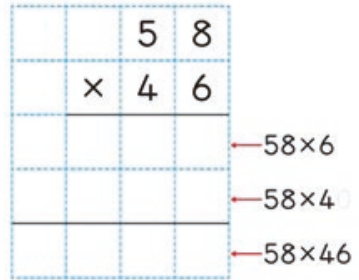

(2) $37 \times 63$

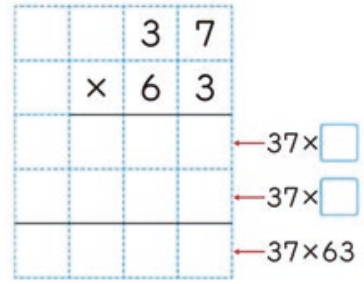

4 Let's think about how to multiply $35 \times 70$ in vertical form.

(1) Explain how the following two children multiply in vertical form.
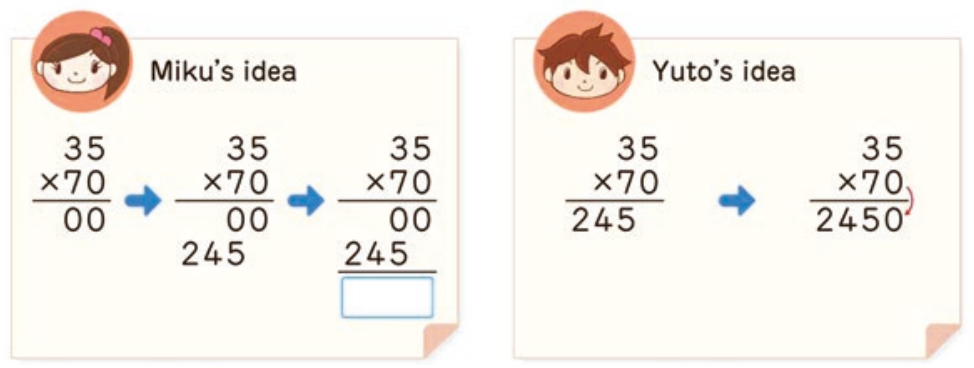

Fig. 7.17 Gakko Tosho (Hitotsumatsu, 2005), Grade 3, Vol. 2, p. 63; and Gakko Tosho (Isoda, Murata, 2011), Grade 3, Vol. 2, p. 67 
Let's make problems by filling the $\square$ with a number.

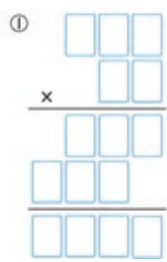

(2)

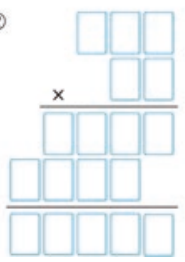

Are the following calculation in vertical form correct? If there are any mistakes in the following multiplications, correct them.

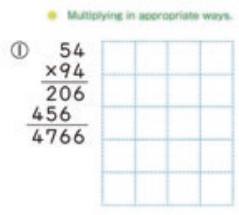

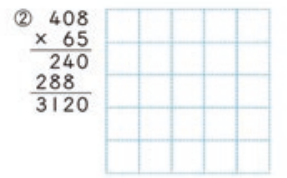

Fig. 7.18 The task on the left side asks students to pose the question to others, and the task on the right side asks students to find mistakes in others' answers. The tasks itself include the objective: Construct viable argument and critique reasoning of others on CCSS.MATH. (2010), USA

These tasks can be solved by using what the students have already learned from the previous tasks. The following Fig. 7.18 are parts of the last exercise (Fig. 7.18). ${ }^{33}$

In this task sequence, teachers ask students to use what they have already learned to justify their ways of calculation. For developing students who learn mathematics by and for themselves, a Task 1-style task is well known to focus their mind-set on the inquiry of extension. Tasks are sequenced for enabling students to extend their ideas by using what they have already learned. Posing question to others and critiquing other students' ideas are also enhanced in the textbooks.

\subsection{Final Remarks}

This chapter has illustrated the extension and integration of multiplication from single digit to multidigit by using vertical form with the base ten system and a multiplication table (see Fig. 1.1 in Chap. 1 from Meaning of B to Procedure B). It has also discussed how students are able to integrate the definition of multiplication by measurement (a groups of groups; see Chap. 3), which supports repeated addition, with the base ten place value system (see the allow ' $\uparrow$ ' on Meaning B n Fig. 1.1

\footnotetext{
${ }^{33}$ As mentioned in Chap. 1, the task sequences in Japanese textbooks are written under the extension and integration principle. Ordinal task sequence is from specific to general like Fig. 4.27 in Chap. 4. This process is also explained as the processes of both conceptualization of procedures and procedurization of concepts (see Chap. 1, Fig. 1.1). Gaining proficiency in the procedure is necessary for further conceptualization. Thus, there is a rich set of exercises at the end of every chapter in the textbook which maximize the proficiency for operations. The task sequence of the exercise for proficiency can be written from general to specific instead of from specific to general in cases; for example, after learned long division, the task sequence $85 \div 7,68 \div 3,54 \div 5$ in exercise, is written in a general-to-specific form as for adaptation of an algorithm (Fig. 7.18, Gakko Tosho, 2011, Grade 4, Vol. 1, p. 46): On $85 \div 7,8-7 \times 1=1,15-7 \times 2=1$; On $68 \div 3,6-3 \times 2=0,8-3 \times 2=2$. On $54 \div 5,5-5 \times 1=0,4$. Isoda learned this from Prof. Tadao Kaneko at the textbook editorial meeting.
} 
coming from the outside of figure). The students are confident of what they have learned about addition and subtraction in vertical form (column methods) under the base ten system (see the allow ' $\uparrow$ ' on Procedure B in Fig. 1.1).

Section 7.1 discussed historical possibilities explaining why multiplication in English-speaking and Spanish-speaking countries involves a contradiction, which has been recursively discussed since posed questions in Chap. 2 and it is the answer from the origin of contradiction for the questions.

In relation to the Japanese approach and lesson study discussed since Chap. 1, the explained task sequences in Sects. 7.3 and 7.4 were developed through experiences of lesson study by a number of teachers, and some of them were embedded into textbooks with the following hidden principles. ${ }^{34}$ The first principle is the sequence of extension from the special/simple case to the general/complex case which enables students to use learned knowledge and develop their learning of mathematics by and for themselves (See Chap. 1, Fig. 1.1). The second principle is the task sequence of mathematical necessity ${ }^{35}$ for enabling students to solve mathematical tasks by themselves, having further expectations of mathematical development and its integration. The third principle is the task sequence that enables students to appreciate their progress through collaborative problem solving with others. ${ }^{36}$ Last principle is related with the objective: Construct viable argument and critique reasoning of others on CCSS.MATH. (2010), USA. These principles were explained by the general principle "Extension and Integration" on Japanese curriculum. On the context of reinvention principle by Freudenthal (1973), it can be said as mathematization because it asking students to reorganize mathematics by and for themselves. These are also seen in Sect. 7.3 which was written by Mr. Muramoto's lesson study group, prepared for his school-based lesson study.

Sections 7.2, 7.3, and 7.4 are an illustration of the Japanese approach to designing lesson study which is mentioned in Chap. 1 with its theoretical background. The example provided by Mr. Muramoto illustrates that Japanese lesson study is a reproducible

\footnotetext{
${ }^{34}$ These principle is subsequents of general principle: extension and integration (see Chap. 1). The first principle can be recognized if readers read students' textbooks on the principle. The second and third principles are usually explained in teachers' guidebooks. The following textbooks are clearly written from the students' perspective: Isoda and Tall (2019), Junior High School Mathematics, Vols. 1-3, Tokyo, Japan: Gakko Tosho.

${ }^{35}$ In French didactics (Artigue, 2014), a priori analysis is also discussed to make clear the significance: in so many cases, it is based on pure mathematics. On the other hand, the Japanese terminology orients teachers to be able to distinguish conceptual differences in teaching content in the curriculum, such as different meanings of fractions. The mathematical necessity of introducing fractions is explained by using the terminology "dividing fraction, operational (measurable) fraction, and fraction with quantity" (See Chap. 4, Figs 4.22 and 4.23).

${ }^{36}$ In Mr. Muramoto's lesson, the students discuss different ideas for multiplying $23 \times 3$, such as $9 \times 3+9 \times 3+5 \times 3,10 \times 3+10 \times 3+3 \times 3$, and $20 \times 3+3 \times 3$. They appreciate every idea and the last one is more economical, being related to the base ten system and the memorized multiplication table. These insights are possible under the task sequence in his unit plan and the curriculum with acquisition as learned knowledge and skills.
} 
science $^{37}$ (Isoda, 2015a, 2015b) that produces better practice through exploring "why" for objective and "what" for teaching materials with a sequence under the shared curriculum. In Chap. 1, the Japanese theories used to design lessons are categorized as follows: the theory to clarify the aims and objectives in every class such as the national curriculum standards and mathematical thinking, the terminologies to distinguish conceptual differences in teaching content, the theory to establish the curriculum sequence and task sequence, and the theory to manage the lesson such as Problem Solving Approach. Mr. Muramoto's lesson plan (described in Sects. 7.2.2, 7.2.4, and 7.3) was written based on these theories as background knowledge and shows how Japanese teachers deeply plan their lessons through the year. ${ }^{38}$

Sect. 7.5 illustrated the trajectory for enabling students to develop multiplication in vertical form beyond repeated addition using what they have learned such as the definition of multiplication by measurement, addition and subtraction in vertical form with the base ten place value system, and block diagrams with splitting for decomposing numbers. It is the exemplar for how Japanese teachers plan and teach learning how to learn as a part of human character formation by using what students have learned with considering how students extend their ideas for performing extended tasks. Japanese teachers who are engaging in subject based lesson study usually try to develop their lessons to develop the students who construct viable argument and critique of others. In Chap. 1, it is explained as Dialectic Approach on Fig. 1.4. Stigler and Hiebert (1999) en-lighted Japanese Problem Solving Approach through the comparison of classroom videos among USA, Germany and Japan. On the context of learners perspective study by Clarke, Keitel, and Shimizu, Sekiguchi, (2006) illustrated clearly from the perspective of Japanese classroom culture by using his analytical framework for classroom norms. Through the part I from Chap. 1 to Chap. 7, this book informed the unknown Japanese theories which teachers use for designing their practice to realize their objectives for developing students. It is the originality of this book as well as the meanings and roles of multiplication in elementary mathematics curriculum and its historical origin.

\footnotetext{
${ }^{37}$ Even though in this case, teachers use the same textbook and task sequence to minimize their preparations, the teachers have to reinvent the objective for the teaching content. By sharing Japanese theories through lesson study, they usually find ideas for teaching such as the meaning of a task that is really problematic for children and is the subject of discussion (See Chap. 1, Fig 1.3).

${ }^{38}$ This is the case in subject-based lesson study. Mr. Muramoto is a member of several subjectbased lesson study groups, such as Isoda's lesson study group, based on the meaning (concept) and procedure mentioned in Chap. 1, Fig 1.1. In Japan, in the context of lesson study, teachers do not use the custom of writing references on their lesson plans like academic research papers even though they have studied various theories. In the teacher training program provided by the teacher training center, universities, and so on, they have a lot of opportunities to study design theories, which are explained in Chap. 1.
} 


\section{References}

Anonymous authors. (10th-2nd centuries BC). Jiǔzhāng suànshù [The nine chapters on the mathematical art]. Han Dynasty.

Anonymous authors. (186 BCE). Suàn shù shū [A book on numbers and computations]. The Zhangjiashan Han bamboo texts. Hubei Province, Han Dynasty Chinese.

Araya, R., Isoda, M., Rafael, O., Inprasitha, M. (to appear). Computational Thinking; A Curriculum Framework for a Digital Society on APEC. Journal of Southeast Asian education.

Arcavi, A. (1994). Symbol sense: Informal sense-making in formal mathematics. For the Learning of Mathematics, 14(3), 24-35.

Arcavi, A., \& Isoda, M. (2007). Learning to listen: From historical sources to classroom practice. Educational Studies in Mathematics, 66, 111-129.

Artigue M. (2014) Didactic Engineering in Mathematics Education. In: Lerman S. (eds) Encyclopedia of Mathematics Education. Dordrecht, Netheland: Springer, 159-162.

Cajori, F. (1928). Notation in Elementary Mathematics. La Sale, Ill, USA.: The Open Court Publishing Company.

CCSS.MATH. (2010). Common Core State Standards for Mathematics. Common Core State Standards Initiative. Retrieved from http://www.corestandards.org/wp-content/uploads/Math_Standards.pdf.

Clark, G. (1682). Oughtredus explicatus, sive, Commentarius in ejus Clavem mathematicam: cui additce sunt Planetarum observationes \& horologiorum constructio. London, UK: Typis Milonis Flesher, Veneunt apud Ric. Davis, bibliopolam Oxoniensem.

Clements, D., \& Sarama, J. (2004). Learning trajectories in mathematics education. Mathematical Thinking and Learning, 6, 81-89. https://doi.org/10.1207/s15327833mtl06021.

Cullen, C. trans. (2004). The Suan Shu Shu: A Translation and Study of the Earliest Chinese Mathematical Text. Cambridge: Needham Research Institute.

Dauben, J. (2008). Suàn shù shū [A book on numbers and computations]. (English translation with commentary.). Archive for History of Exact Sciences, 62(2), 91-178.

Hitotsumatsu, S. (2005). Study with your friends: Mathematics for elementary school (vol. 11). (English translation of Japanese textbook.) Tokyo: Gakko Tosho.

Hulbert, E. T., Petit, Marjorie, M., Ebby, C. B., Cunningham, E. P., Laird, R. E. (2017). A focus on multiplication and division: Bringing research to the classroom. NY, USA: Routledg.

Inprasitha, M, \& Isoda, M. (2010). Study with your friends: Mathematics, grade 1-6. Kohn Kaen: Khon Kaen University. (In Thai, translated by M. Inprasitha with supervision of M. Isoda) เรียน คณิตศาสตร์ กับ เพือนๆ: คณิตศาสตร์ สำหรับ ระดับ ช้น ประถมศึกษา, แปลและเรียบเรียง, ไมตรี อินทร์ประสิทธ์; ทีปรึกษา, มะซะมิ อิโซะดะ (Masami Isoda); [ผู้แปลและเรียบเรียง, ไมตรี อินทร์ประสิทธ์ และนายอรรค อินทร์ประสิทธ์] [ขอนแก่น]: [โรงพิมพ์คลังนานาวิทยา]).

Isoda, M. (2012). Introductory chapter: Problem solving approach to develop mathematical thinking. In M. Isoda \& S. Katagiri (Eds.), Mathematical thinking: How to develop it in the classroom. Singapore: World Scientific.

Isoda, M. (2015a). The science of lesson study in the problem solving approach. In M. Inprasitha, M. Isoda, P. Wang-Iverson, \& B. Yap (Eds.), Lesson study: Challenges of mathematics education (pp. 81-108). Singapore: World Scientific.

Isoda, M. (2015b). Dialectic on the problem solving approach: Illustrating hermeneutics as the ground theory for lesson study in mathematics education. In S. J. Cho (Ed.), Selected regular lectures from the 12th International Congress on Mathematical Education (pp. 355-381). Cham: Springer.

Isoda, M. (2016). Introducción. El enfoque de resolución de problemas para desarrollar el pensamiento matemático. In M. Isoda and S. Katagiri, (coord. de Roberto Araya; A. Jeldrez, Trans.) Pensamiento matemático: Cómo desarrollarlo en la sala de clases. Santiago: CIAE, Universidad de Chile.

Isoda, M. and Cedillo, T. (2012). Study with your friends: Mathematics for elementary school (vol. 11). (Spanish translation of Japanese textbook.) Mexico: Pearson.

Isoda, M. and Murata, A. (2011). Study with your friends: Mathematics for elementary school (vol. 12). (English translation of Japanese textbook.) Tokyo: Gakko Tosho. 
Isoda, M., \& Nakamura, T. (Eds.). (2010). Mathematics education theories for lesson study: Problem solving approach through extension and integration. Special issues for EARCOME 5. Tokyo: Journal of Japan Society of Mathematical Education.

Isoda, M., Shimizu, S., Loipha, S., \& Inprasitha, M. (Eds.). (2007). Progress report of the APEC project: "Collaborative Studies on Innovations for Teaching and Learning Mathematics in Different Cultures (II): Lesson Study focusing on Mathematical Thinking.". Tsukuba: Center for Research on International Cooperation in Educational Development (CRICED), University of Tsukuba. Retrieved from http://www.criced.tsukuba.ac.jp/math/apec/apec2007/ progress_report/

Isoda, M., \& Tall, D. (2019). Junior high school mathematics (Vol. 1 3). Tokyo: Gakko Tosho.

Jochi, S. (2003). Reconsideration of "The Yang Hui Suan Fa". Kôkyûroku Bulletin of Research Institute for Mathematical Science of Kyoto University, 1317, 71-79.

Managao, D., Ahmad, J., \& Isoda, M. (2017). SEAMEO Basic Education Standards (SEA-Bes): Common Core Regional Learning Standards (CCRLS) in Mathematics and Science. Penang, Malaysia: SEAMEO RECSAM.

MEXT (2017a). Elementary school teaching guide for the Japanese course of study: Mathematics (grade 1-6) (written in Japanese). Retrieved from http://www.mext.go.jp/a_menu/shotou/newcs/1387014.htm

MEXT (2017b). Japanese course of study for elementary school (grade 1-6) (written in Japanese). Retrieved from http://www.mext.go.jp/component/a_menu/education/micro_detail/_icsFiles/ afieldfile/2017/05/12/1384661_4_2.pdf

Muramoto, H. and Okubo, K. (2007). Multiplication algorithm, 3rd grade mathematics lesson plan. In APEC-Tsukuba International Conference. Retrieved from http://www.criced.tsukuba. ac.jp/math/apec/apec2007/lesson_plans/Hideyuki_Muramoto.pdf

National Research Council (2011). Report of A Workshop on the Pedagogical Aspects of Computational Thinking. Washington, D.C: The National Academic Press.

Oughtred, W. (1667). Clavis Mathematicae Denuo Limata, Sive Potius Favraicata. Oxford, UK: Oxoniæ.

Oughtred, W. (1694). Key of the Mathematics. London, UK: Printed for John Salusburp.

Peet, E. (1923). The Rhind mathematical papyrus: British Museum 10057 and 10058. Liverpool: University Press of Liverpool.

Ramsey, S. (1892). English Language and English Grammar: An Historical Study. London UK: G.P. Putnam's Sons.

Reisch, G. (1504). Margarita philosophica. Argentineñ: Opera Joannis Schotti.

Reys, R., Lindquist, M., Lambdin, D., \& Smith, N. (2012). Helping children learn mathematics (10th ed.). Hoboken: Wiley.

Seki, T. (1674). Hatsubi-Sanpō. From Fujioka in Gunma Prefecture, Edo Period.

Sekiguchi, Y. (2006). Mathematical Norms in Japanese Mathematics Lessons. Clarke, D. J., Keitel, C., and Shimizu, Y. edited. Mathematics Classroom in Twelve Countries: The insiders' perspectives (247-261). Rotterdam, The Netherlands: Sense Publishers.

Sigler, L. E. (2002). Fibonacci's Liber Abaci: A translation into modern English of Leonardo Pisano's book of calculation. New York: Springer.

Tall, D. (2013). How humans learn to think mathematically: Exploring the three worlds of mathematics (learning in doing social, cognitive and computational perspectives). Cambridge: Cambridge University Press.

Treffers, A., Nooteboom, A., \& de Goeij, E. (2001). Column calculation and algorithms. In M. van den Heuvel-Panhuizen (Ed.), Children learn mathematics (pp. 147-171). Utrecht: Freudenthal Institute, Utrecht University.

van den Heuvel-Panhuizen, M. (2001). Children learn mathematics. Utrecht: Freudenthal Institute, Utrecht University.

Vygotsky, L. (Hanfmann, E. \& Vakar, G trans) (1962). Thought and language: Studies in communication. Boston, MA: MIT Press. 
Yáng, H. (1274, 1275). Yanghuī Suan Fă (Detailed analysis in the mathematical rules, numerical arrays). Sòng Dynasty. Used (宋)揚輝編「宋揚輝等法 7巻」慶州府, 宣徳8 [1433]. Retrieved from https://www.tulips.tsukuba.ac.jp/limedio/dlam/B10/B1039351/1.pdf

Zhū Shìjié, P. (1299). Suànxué Qìméng (Introduction to computational studies). From Beijing area, Mandarin society, Yen Dynasty. Used (元)朱世傑撰「新編笄學啓蒙 3巻坿緆括 1巻」李朝初期. Retrieved from https://www.tulips.tsukuba.ac.jp/limedio/dlam/B10/ B1039397/1.pdf

Open Access This chapter is licensed under the terms of the Creative Commons Attribution 4.0 International License (http://creativecommons.org/licenses/by/4.0/), which permits use, sharing, adaptation, distribution and reproduction in any medium or format, as long as you give appropriate credit to the original author(s) and the source, provide a link to the Creative Commons licence and indicate if changes were made.

The images or other third party material in this chapter are included in the chapter's Creative Commons licence, unless indicated otherwise in a credit line to the material. If material is not included in the chapter's Creative Commons licence and your intended use is not permitted by statutory regulation or exceeds the permitted use, you will need to obtain permission directly from the copyright holder.

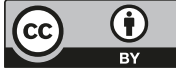

